\title{
De la raíz a las puntas (con un insecto en medio): la poesía erótica de Diego Hurtado de Mendoza reloaded
}

\author{
J. Ignacio Díez \\ Universidad Complutense \\ igdiez@ucm.es
}

Recepción: 09/02/2015, Aceptación: 11/03/2015, Publicación: 22/12/2015

Eran hospitalarios, generosos, sencillamente patriarcales, modestamente aristocráticos.

(Ernesto Sábato, Sobre héroes y tumbas)

\begin{abstract}
Resumen
La exclusión de las obras burlescas en la editio princeps de la poesía de Diego Hurtado de Mendoza obedece a un calculado gesto para rescatar la imagen «grave» de un antepasado ilustre del conde de Tendilla. Los preliminares de esta edición apuntan en la misma dirección. El editor del volumen, frey Juan Díaz Hidalgo, solo cita tres de esas obras ( «la azanahoria, cana, pulga y otras cosas burlescas»), lo que obliga a fijar un corpus conservado en los manuscritos. Los tres poemas son inequívocamente de Mendoza, como lo prueba el prólogo del primer editor y la coherencia sistemática de la transmisión manuscrita (a pesar de sus problemas). La pulga, en la fuente que la atribuye a Cetina, incluye amplificaciones que destruyen la credibilidad de esta autoría. La zanahoria, en la tradición bernesca, no sigue ninguno de los dos capitoli de Franzesi. La cana, por último, se transmite en dos versiones, una de ellas amplificada.
\end{abstract}

\section{Palabras clave}

Diego Hurtado de Mendoza; pulga; zanahoria; cana; poesía erótica; Gutierre de Cetina; Mattio Franzesi; Juan Díaz Hidalgo; amplificación; atribución

\begin{abstract}
From the root to the top (with an insect in between): the erotic poetry of Diego Hurtado de Medoza reloaded

The exclusion of the burlesque works from the editio princeps of the poetry of Diego Hurtado de Mendoza can be interpreted as the attempt to recuperate the "grave» image of an illustrious ancestor of the Count of Tendilla. Preliminary pieces of this edition show a similar intention. The editor of the volume, frey Juan Díaz Hidalgo, only mentions three of these works («the carrot, white hair, flea and other burlesque things»),
\end{abstract}


which would require the establishment of the corpus preserved in the manuscripts. The three texts are unequivocally Mendoza's poems, as evidenced by the prologue of the first editor and the systematic coherence of the manuscript transmission (despite its problems). The flea, in the source that attributes it to Cetina, has amplifications that destroy the credibility of this authorship. The carrot, in the bernesque tradition, does not follow any of the capitoli by Franzesi. The white hair, finally, has been transmited in two versions, one of them amplified.

\section{Keywords}

Diego Hurtado de Mendoza; flea; carrot; white hair; erotic poetry; Gutierre de Cetina; Mattio Franzesi; Juan Díaz Hidalgo; amplification; attribution

\section{Juegos de una princeps tardía}

Entre los escasos méritos de las Obras del insigne caballero don Diego de Mendo$z a$ se cuenta el haber destacado la importancia de las burlas: en el prólogo "Al lector» se mencionan los textos que se excluyen, no sin explicar, por un prurito elemental en quien presume de conocer adecuadamente una obra literaria, las razones que justifican tal exclusión. Así, frey Juan Díaz Hidalgo, antes de publicar los noventa y seis poemas que componen las Obras, nombra «la azanahoria, cana, pulga y otras cosas burlescas». El hecho es que con esos sustantivos el editor reconoce que la fama de Mendoza no se ha basado en los horizontes que va a dibujar su libro — que es, por otro lado, una princeps con numerosos problemas, ${ }^{1}$ entre ellos los treinta y cinco años que la separan de la muerte del autor-, aunque con ese arriesgado movimiento lo que pretenda, obviamente, es apostar por un cambio en los motivos de una justa fama poética. No se trata con ello de socavar el trabajo propio, naturalmente, sino de explicar una recuperación limitada e interesada de la poesía de Mendoza, intento que fracasará a muy largo plazo. En este esfuerzo de reconducir o completar una trayectoria

1. Hurtado de Mendoza (2007: lvii-lxxii). Todas las citas de la poesía de Mendoza proceden de esta edición. 
literaria el compilador combate, y no siempre aprecia en lo que vale, ${ }^{2}$ una bien asentada y riquísima transmisión manuscrita.

Una lectura atenta de los preliminares de las Obras arroja matices importantes para entender el sentido de una princeps que está dedicada, intensamente, a uno de los descendientes de la familia del autor: don Ínigo López de Mendoza, VII conde de Tendilla y V marqués de Mondéjar (Gutiérrez Coronel 1946: II 341). Una misma línea organiza las piezas preliminares (cinco sonetos, ${ }^{3}$ la dedicatoria $\mathrm{y}$ «Al lector»). Entre los sonetos preliminares, el primero, firmado por Miguel de Cervantes, no tiene empacho en ponderar la poesía de don Diego desde una perspectiva única: "premio que le merecen sus escritos / por graves, puros, castos y excelentes» (vv. 3-4). Los cuatro adjetivos aluden a contenidos estéticos y morales, hábilmente unidos en una visión idealista en la que a los cuatro, sin ser sinónimos, se les hace compartir una decisiva carga sémica. «Puros» parecería gozar de una calculada ambigüedad que su situación quiere deshacer, pues la gravedad que le precede y la castidad que le sigue señalan en una muy determinada dirección. Al dedicar la edición a un noble que trataría de usarla para asentar su prestigio con un antepasado tan culto como guerrero, ${ }^{4}$ cinco años después de haber heredado el marquesado y el condado, podría señalarse al mecenazgo editorial. Por eso quizá Antonio Hurtado de Mendoza en la mejor tradición hiperbólica supone en el conde de Tendilla unas habilidades con la espada que la posteridad no ha conservado: ${ }^{5}$ «Si en el ínclito conde de Tendilla / humilla Marte la triunfante

2. En la dedicatoria las Obras del insigne caballero don Diego de Mendoza se presentan como el espejo puro de la fama, frente a los manuscritos: «[...] para que puedan revivir y andar por las manos de los que las desean y estiman, no en borradores y traslados cojos y mal escritos, sino grabadas en láminas de bronce y de oro, que prometan duración de siglos y eternidad de tiempos» (todas las referencias en «Algunos preliminares de la edición príncipe», Hurtado de Mendoza 2007: 657-662). 3. El reparto está muy bien trazado, pues Cervantes canta «a don Diego de Mendoza y a su fama»; Mira de Amescua, «al libro de don Diego de Mendoza»; Antonio Hurtado de Mendoza, «al autor»; Mariana de Vargas, también «al autor»; y «un Grande de España, al conde de Tendilla». Los sonetos tercero y cuarto tienen sin embargo más de un destinatario: el de Antonio Hurtado de Mendoza desde su mismo inicio; el soneto de Mariana de Vargas juega en los tercetos con un paralelismo doble, confuso y forzado: del mismo modo que Alejandro tuvo su Apeles, el conde de Tendilla "canta» a su antepasado («único cisne») al recobrar sus obras pues solo él podía hacerlo (ya que está a su altura: «si cual tú no fuera»). Los problemas de ambos sonetos remiten a dos poetas vacilantes, a un Antonio Hurtado de Mendoza en sus comienzos y quizá a una poeta limitada en el dominio de la técnica de la estrofa-género. Más lograda se percibe la unión de los dos Mendoza en el soneto de «un Grande de España»: los once primeros versos hablan de un Tendilla hoy desconocido y su «intento», que «también al cielo levantado aspira» (vv. 10 y 11), une al antepasado embajador con el aún reciente heredero.

4. "Las obras son del famoso caballero don Diego de Mendoza, en quien se vieron juntas (en igualdad inimitable) las armas y las letras, la gracia y la cortesía, con todas las circunstancias de ingenio y de valor que le pudieron hacer memorable, no solo en las suyas sino en las ajenas y más remotas naciones de la tierra» (dedicatoria).

5. López de Mendoza fue también marqués de Valfermoso y «alcaide perpetuo y general de la Alhambra de Granada y grande de España nato [...] viudo de su mujer, ingresará en la Compañía de Jesús y murió novicio el año 1647» (Gutiérrez Coronel 1946: II 341-342). 
espada [...] / goza del uno la mejor cuchilla / que honró a Castilla y asombró a Granada» (vv.1-2 y 5-6). El soneto añade algo más sobre los libros y traza una clara conexión con el ilustre antepasado para incrementar la gloria del dedicatario, en una suerte de muy provechosa simbiosis: «Libros del conde a su valor tenemos, / en vos la gloria, que don Diego aumenta, / pues famoso otra vez por vos le vemos» (vv. 12-14). El soneto que firma Mariana de Vargas y Valderrama también se acoge al camino familiar, heráldico y de prestigio que une al conde de Tendilla de 1610 con don Diego Hurtado de Mendoza, hijo del segundo conde: «Al tronco ilustre de donde ha salido / vuelves el bello fruto de una rama, / dándole eterno nombre y nueva fama, / por tronco, rama y fruto merecido" (vv. 1-4). Por su parte, frey Juan, en «Al lector», no solo insiste en el «fruto», sino que poda ante los lectores la «rama» que se inserta en el poderoso «tronco»: ${ }^{6}$

En sus obras de burlas (que por dignos respetos aquí no se ponen) mostró tener agudeza y donaire, siendo satírico sin infamia ajena, mezclando lo dulce con lo provechoso. La azanahoria, cana, pulga y otras cosas burlescas, que por su gusto o por el de sus amigos compuso, por no contravenir a la gravedad de tan insigne poeta no se dan a la estampa; y por esto, que ya por no ser tan comunes, serán más estimadas de quien las tenga y las conozca.

El quinto y último soneto, firmado solo por «un grande España» (quizá un amigo del dedicatario que era, como se ha visto, «grande de España nato» y quizá también un soneto convenientemente de encargo) se abre y se cierra con una mención de la envidia, en una alusión que podría explicar el anonimato del autor:

Tú en quien mostró la envidia macilenta

su furia toda y todo su despecho,

fuego que acrisoló en tu heroico pecho

el oro del valor que te sustenta [...]

Con esto de los dos tendrá la fama

conocido lugar, sublime asiento,

donde la envidia muere, el tiempo [e]xpira

(vv. 1-4 y 12-14).

6. «Creo sin duda que las flores y frutos que ponen a la mesa de nuestros reyes cuando son de su paraíso terrestre, Aranjuez, con particular afición las gustan y miran, considerando que son de los árboles y plantas que por suyos crecen y en su nombre se cultivan. Lo mismo pienso que ha de suceder con las que a V. Excelencia ofrezco, bien como aquellos que son de una de las más felices plantas o ramo que el real tronco de la antiquísima casa de V. Excelencia produjo al mundo" (dedicatoria: la cursiva es mía). Es evidente la conexión semántica con los dos últimos sonetos que también se valen de "tronco», «fruto», y «rama», mientras el cuarto añade "flores» y el quinto «árbol». Por otro lado, en la poesía laudatoria es frecuente recurrir a un puñado de tópicos y por eso las referencias al sol y a la fama son manifiestas en los tres sonetos iniciales. También las «láminas de bronce» del primer soneto se amplían en las «láminas de bronce y de oro» de la dedicatoria. 
De nuevo el explícito (y un tanto torcido) trazo que une a los dos Mendoza en la fama sirve claramente para subrayar un pasado familiar glorioso del que se destaca ahora un "fruto». También la dedicatoria, fechada en la Navidad de 1609, acaba en esa línea: «y V. Excelencia se mostrará, no solo dignísimo sucesor del estado, sino de los altos pensamientos de sus pasados». ¿Se trataría de un regalo que se ha estado componiendo desde que el conde de Tendilla heredara el título? Lo parece.

Pero no solo los sonetos comparten una argumentación, sino que las dos aprobaciones también lo hacen. En la primera, el doctor Cetina explica que «basta ser de tal autor para estar aprobado en sí». Aunque con la pesada carga tópica la aprobación de fray Francisco Tamayo cobra un cierto sentido personal cuando insiste en que la obra no contiene nada «ni malsonante, ni cosa escandalosa, antes muchos avisos prudentes y muchos documentos morales, importantes para la vida humana. Y si todas las naciones han impreso las sentencias de sus filósofos y sabios, bien es nuestra nación tenga en perpetuidad las de un tan prudente y avisado caballero".

Hidalgo maneja, en la arriesgada operación de recuperar una parte de la poesía de Mendoza y excluir otra bien conocida, toda una panoplia de argumentos de alcance muy diverso. El centro sigue siendo el mismo: la "gravedad ${ }^{8}$ y, ahora también, los «dignos respetos»; la primera es del poeta, aunque extiende fácilmente su aura a los descendientes de la ilustre familia, y los segundos son sin duda los «respetos» que merecen tanto el dedicatario y posible mecenas de la edición como subsidiariamente el «lector» (pues «la buena fama infunde respeto»). Queda muy claro, con un criterio que no llama a engaño, que el volumen es buscadamente incompleto, aunque ello no evita una valoración positiva de lo rechazado, en un juego muy sutil. ${ }^{9}$ Las «obras de burlas» de don Diego se adornan de las notas estéticas pertinentes («agudeza» $\mathrm{y}$ «donaire») y de las morales (no hay «infamia ajena» y mezclan, desde una visión extraordinariamente complaciente con lo que no se imprime, «lo dulce y lo provechoso»). ¿Por qué se excluyen entonces? Por razones extraliterarias, pues el nuevo conde de Tendilla no quiere un libro que no le resulte útil, y también por motivos netamente de censura, ya que algunos de los poemas de don Diego no son publicables en $1610 \ldots$ aunque eso el editor ni siquiera necesita mencionarlo. Más sibilino aún frey Juan apunta a una motivación compleja

7. Todas las piezas fechadas de los preliminares lo están muy a finales de diciembre de 1609, excepto el privilegio para Castilla y las dos aprobaciones (en abril y marzo de ese año, respectivamente). El libro se vendió mal: en 1623 Robles tiene aún 910 ejemplares (Lasperas 1979: 111).

8. Así acaba el soneto que le dedicó Aretino a don Diego con motivo del retrato de Tiziano: «ma i pensier alti de la nobil mente / che, in le sue gravità raccolta e intera, / tanto scorge il futur quanto il presente» (González Palencia - Mele 1941-1943: I 229).

9. Aunque no creo que lo sea tanto que se le pueda dar la vuelta: «These last lines are a virtual invitation to the reader to search out Mendoza's burlesque poetry, since Hidalgo reports that they are rare items» (Darst 1987: 27). 
en la composición de «la azanahoria, cana, pulga y otras cosas burlescas», pues quizá la raíz está en el "gusto» de «sus amigos», con lo que don Diego de Mendoza, en un retrato donde el poeta mismo comparte las notas de sus versos "graves, puros, castos y excelentes», sería un hombre atraído por un círculo difuso, desconocido y poco saludable en el fondo. El rechazo de los textos salva, una vez más, la calidad literaria y moral del autor pues esos poemas contravienen «la gravedad de tan insigne poeta» (que en la dedicatoria goza también de «la alteza, la facilidad y agudeza de ingenio»). Por eso, con la autoridad del nuevo conde de Tendilla, con la de frey Juan, que es "capellán y músico de cámara de Su Majestad», y con la de los cinco sonetistas (más la inestimable ayuda de la censura civil) esas obras «no se dan a la estampa». Y de lo que parecería un mal, se deriva un bien, en ese juego sutil de tejer y destejer, de rechazar y apreciar (en los terrenos en los que se puede), pues la ocultación a la imprenta evitará a estos textos la vulgaridad del común y las poesías "serán más estimadas de quien las tenga y conozca», de nuevo en un juego de bibliofilia (que prestigia los manuscritos) y de estética literaria (que valora el conocimiento de unos textos adornados de las cualidades ya mencionadas). Hidalgo, que se ha nutrido de la tradición manuscrita, despliega un doble juego de mucho interés, pues dice cosas distintas al conde de Tendilla en su dedicatoria y al lector, distintas y quizá complementarias, ya que nada impide que «los traslados cojos y mal escritos» de una sean en el prólogo las copias «más estimadas de quien las tenga y conozca», es decir de los lectores. Mucho cálculo manifiesta el editor para satisfacer al mecenas y a los compradores.

Alberto Blecua, en un artículo muy ingenioso, apuesta por la posible autoría de Cervantes no solo de las palabras "Al lector», sino de buena parte de los preliminares. El argumento que le parece incontrovertible para ello es el uso del sintagma «secuaces de Apolo» ${ }^{10}$ que, por otro lado, no está expreso (se puede sobreentender que los secuaces son de Apolo, pero también de las Musas o de ambos): «Pero si de otro mejor original le tuvieres, purifícale y enmiéndale; aunque de cualquiera suerte al nombre de don Diego de Mendoza se inclinará la majestad de Apolo, la gravedad de las musas y la arrogancia de todos sus secuaces. Vale». Si en 2005 hizo un furor muy comprensible el CD que acompañó la edición del Quijote que Rico y su equipo publicaron en Crítica, pues abría amplísimas posibilidades de explorar el vocabulario cervantino, el desarrollo del CORDE, todavía en proceso, ha venido a abrir aún más y a perfilar esas búsquedas. Así «secuaces» aparece en numerosos textos anteriores al Viaje del Parnaso, probando de ese modo la no exclusividad cervantina ni del término ni del sintagma despectivo. ${ }^{11}$

10. Aunque haya un «[...] argumento más sólido y creo, irrefutable. Me refiero a los "secuaces de Apolo"», al final del trabajo se impone la cautela: «No confundamos la verdad con lo verosímil» (Blecua 2005: 6).

11. Alonso de Santa Cruz, c. 1550, «secuaces de la secta luterana»; Sebastián de Horozco, c. 1550, «secuaces de su doctrina»; Lorenzo de Cepeda, Testimonio de don Lorenzo de Cepeda a la santa (1578), «secuaces de Pizarro»; Pedro Cieza de León, 1553-84, «secuaces de Pizarro»; siete 
No hay mucho que decir ni de frey Juan Díaz Hidalgo, cuya existencia sí está documentada, ni de la misteriosa Mariana de Vargas y Valderrama, ${ }^{12}$ ni del «Grande de España». Pero conviene detenerse en otros datos. Antonio Hurtado de Mendoza cuenta con veintitrés años cuando escribe su soneto, seguramente aún es paje al servicio del conde de Saldaña y este es su segundo poema publicado. Está en Madrid desde 1601, es amigo de Lope, de Vélez de Guevara, de Mira de Amescua... y Cervantes lo cita en su Viaje del Parnaso. ${ }^{13}$ La presencia de un poeta tan joven en las Obras ¿a qué se debe? ¿A su apellido, quizá a un contacto con el conde de Tendilla, con Mira de Amescua o con Cervantes? Antonio Mira de Amescua también disfrutaba de una gravedad admirable, según dice Cervantes pocos ańos después de las Obras en los preliminares de las Ocho comedias y ocho entremeses. Pero interesa mucho más saber que estudió en Granada, que está en Madrid desde 1606, que fue nombrado capellán de la Capilla Real de Granada el uno de septiembre de 1609, para lo cual tuvo que recibir el «juicio favorable» de un expediente de limpieza de sangre (el 20 de diciembre de ese mismo año), y, sobre todo, que en el pleito por el asesinato de su padre ganó una indemnización precisamente en 1610 (Castilla 1998: 30-33 y Martínez Morán 2011). ¿Intervino en algo la familia Mendoza? ¿Tiene nexos el flamante capellán con el otro capellán real que firma la edición? La conexión con Cervantes pudo no ser buena, pues Mira de Amescua está más situado en el círculo de Lope. ${ }^{14}$ Por último el capellán de la Capilla real de Granada se va a Nápoles con el conde de Lemos en 1610, quizá por su relación con los Argensola en Madrid...

Según la hipótesis de Blecua, que sigue a Rico en la atribución de «Al lector» a Cervantes, el alcalaíno pudo escribir también la dedicatoria, los dos sonetos finales y pudo incluso haber compilado los poemas de Mendoza. Pero haya sido así o hayan funcionado las relaciones de un miembro de una poderosa familia que

ejemplos en Juan de Pineda, de 1589 (secuaces de la hoz, de Hércules, de Platón, de Zenón, de Anaxágoras, de Pitágoras y de su doctrina); dos de fray Prudencio de Sandoval, de 1604-18 (de las nuevas doctrinas, de la mala doctrina); Luis de Mármol y Carvajal escribe «secuaces de Mahoma» en 1600, sintagma que hará fortuna (en el Persiles; Jerónimo Alcalá, El donado hablador Alonso, mozo de muchos amos. Segunda parte, 1626, etc.); Góngora emplea «secuaces de Diana» en sus romances, etc. (consulta del 27 de enero de 2015). Véase infra la nota 60.

12. No he conseguido encontrar ningún dato sobre Mariana de Vargas y Valderrama, pero sí he averiguado que el dedicatario de las Obras del insigne caballero don Diego de Mendoza estuvo casado con Ana de Cabrera Vargas y Tapia, «hermana de don Antonio de Vargas, primer marqués de la Chavela y espía mayor de Castilla» (Gutiérrez Coronel 1946: II 341). Ignoro si hay alguna relación. 13. No parece posible documentar un encuentro en una academia, aunque bien pudo producirse, quizá en la del conde de Saldaña (con sesiones desde 1605), en la Academia Selvaje («patrocinada por don Francisco de Silva y Mendoza, en su palacio de la calle de Atocha, donde a principios del siglo Xviı se reunía lo más granado de la cultura literaria madrileña», Sánchez-Molero 6045), o en la de Sebastián Francisco de Medrano (King 1963: 43 y 49-51), aunque para mis intereses la más importante es la primera, pues las otras dos son posteriores a las Obras.

14. Castilla supone un posible encuentro de Mira de Amescua con Cervantes en Guadix en 1594-95 (1998: 25). 
hereda de su tío sin descendencia (el VI conde de Tendilla había fallecido en 1592 y Luis Hurtado de Mendoza, su padre, no tuvo más hijos), como creo, lo importante es la consonancia de los preliminares, de todos los preliminares, en trazar un dibujo monocromo de la poesía de don Diego para poner el libro al servicio del actual conde de Tendilla, sin duda tan grave como imaginaban a su antecesor.

Una lectura del cuerpo del volumen, tan atenta como la de los preliminares, detecta que la selección de textos serios sí puede permitirse aceptar, entre la multitudinaria compañía de casi un centenar poemas, alguno limpiamente erótico. El lector tropieza con un poema que podría contravenir la famosa "gravedad de tan insigne poeta", aunque lo hace de una manera muy atenuada: la doble redondilla «Venus se vistió una vez» goza tanto del prestigio de lo clásico como de lo escueto de la propuesta (Díez 2003: 98-99). No cabe pensar que frey Juan se ha dejado engañar al incluir este poema, pues el buen olfato le permite excluir, gracias a las finas redes censoras, otro poema, también de métrica castellana, muy circunstancial y muy juguetón con la pegajosa corrosión erótica que las Obras del insigne caballero don Diego de Mendoza pretende combatir («El bombodombón»). ${ }^{15}$ También contravienen el axioma de la gravedad las dos epístolas a María de Peña, textos acogidos a la poética divertida de la epístola horaciana, aunque muy alejados de la burla pura y dura. ${ }^{16}$

Frey Juan, con sus esfuerzos y sus rechazos y con sus cuidadas precauciones, lega a la posteridad el problema de la reconstrucción de ese canon erótico que su edición ha dejado limitado a varios textos, el impreso y tres simplemente mencionados con un único sustantivo (demasiado elocuente — «azanahoria, la cana, la pulga»— pero no tanto como otros posiblemente aún más, pues «En loor del cuerno» quedaría reducido a «el cuerno» en la educada y breve enumeración del editor), aunque ha abierto la puerta a las especulaciones y los problemas filológicos con esas «otras cosas burlescas», que son, en opinión de Morel-Fatio (y de Ludwig Lemcke, a quien sigue) «la partie la plus remarquable des oeuvres poétiques de Mendoza». ${ }^{17}$

15. Rada (1990: 243-244), Hurtado de Mendoza (1995: 25-26) y Díez (2003: 102-103). El poema, con su tinte erótico e irónico, se podría encuadrar dentro de los poemas cancioneriles dedicados a «la enfermedad de la dama» (Alonso 2001: 19 y ss.): los recuerda o se inspira en ese modelo. 16. En la segunda epístola a María de Peña («El pobre peregrino, cuando viene», 46-56) hay pasajes de una suerte de historia sexual que no se escapan al ojo vigilante del anotador de un manuscrito del que trato a continuación (Díez 2007): marca con «male» algunos versos («Dentro ha hecho experiencia en la labor / enhilando una aguja y, más desnuda, / ha mostrado si el vientre es paridor, // si es flaca o gorda en carnes o nervuda, / coja, manca, contrecha de algún vicio, / loca, simple, atronada, sorda muda. // La madre y las parientas del novicio, / por conocer mejor si era de prueba, / le mandaron hacer este ejercicio», vv. 244-252). Otros fragmentos con elementos sexuales, en epístolas y en fábulas mitológicas, en Hurtado de Mendoza (1995: 27-31).

17. Morel-Fatio supone a don Diego, como autor del Lazarillo, «particulièrement apte à trater le genre burlesque» (1875: 64). Pero, al margen de la atribución del Lazarillo, revivida con fuerza en estos últimos años, «lo importante, y porque tenía autoridad para ello, es la proyección y novedad que tiene su poesía desmitificadora y burlona» (Prieto 1984: 101-102) como adelanto barroco. 


\section{Edición y crítica: dos trayectorias reveladoras y confluyentes}

Los poemas que Hidalgo rechaza son tenidos como «burlescos» y «satíricos» y tardarán casi tres siglos en ser recuperados por la imprenta. Este "olvido» impreso es una obvia negación, un intento de borrado, que confía en los poderes civiles para mantener la imprenta al servicio de causas tan "graves» como los versos de don Diego que el conde de Tendilla quiere a su servicio. La férrea censura solo es combatida con relativo éxito a partir del siglo XIX, aunque incluso entonces la reacción continúa bajo otras formas, como ha ocurrido con La Lozana, por ejemplo, "condenada al olvido por juicios severos del XIX sentados por nombres de gran envergadura como Menéndez Pelayo» (Botta 2006: 80). Sin embargo, todavía dentro del período romántico, un español alejado ideológicamente de gran parte de sus compatriotas, Luis de Usoz y Río, recupera en Londres el Cancionero de obras de burlas provocantes a risa (Díez 2015). Los poemas de Mendoza tardarán algo más en llegar a los tórculos, muy avanzado el XIX, gracias a los esfuerzos de un investigador francés y a la existencia del manuscrito 258 del fondo español de la Biblioteca Nacional de París, cuyos dieciséis poemas burlescos editados por Morel-Fatio son rápidamente recuperados en España por un editor que se esconde (Hurtado de Mendoza 1876) y que invierte el orden francés de "poésies burlesques et satiriques». Con una distancia de tres siglos desde la muerte del poeta quedan muy lejos los intereses familiares y los intentos de dignificación hacia quien fuera embajador de Carlos V en Venecia y en Roma. En otro contexto, también cultural y literario, es, sin embargo, la mano de un norteamericano -y no es casual que sean los extranjeros y los españoles en el exilio quienes recuperen un tipo de poesía que se llama burlesca- quien da a luz la primera edición con ínfulas de completa de la poesía de don Diego. Pero William Knapp (más que probable editor de Hurtado de Mendoza 1876) también se muestra partidario del gueto, con las escasas excepciones de alguna sátira y de "El bombodombón", de modo que las «Poesías satíricas y burlescas» aparecen concentradas en una sección al final del volumen (Hurtado de Mendoza 1877: 433-478, muy elocuentemente tras las «Poesías varias» y antes del «Apéndice», es decir, en el último sitio posible): no se trata ya de una explícita condena moral (pues ni siquiera Hidalgo la formula como tal), sino del recurso a la condición inédita de los poemas. Por primera vez, aunque en el furgón de cola, el lector puede acercarse a los poemas de Mendoza, «la azanahoria, cana, pulga y otras cosas burlescas», en letras de molde en la que se anuncia con orgullo como la "primera edición completa». No puede olvidarse tampoco la impagable contribución de Raymond Foulché-Delbosc al mejor y desprejuiciado conocimiento de la obra de Mendoza.

Con todo, la incomodidad de los poemas «satíricos y burlescos» ya no obedece a los pujos de un estricto y noble pariente, ni a las salvíficas normas de una censura civil y eclesiástica, pero de algún modo, a pesar del tiempo transcurrido, estos poemas siguen demostrando que no son fáciles de integrar entre los versos de amor, petrarquistas o no, y no dan con su lugar en algunas ediciones del siglo xx, 
o solo encuentran un acomodo incómodo. En la edición de posguerra de Bohigas el mismo título y el reconocimiento del colector ${ }^{18}$ anuncian una severa poda en toda regla que deja escasos frutos al final del libro. Tampoco hallan mucho hueco en la edición de Díaz Larios y Gete Carpio (Hurtado de Mendoza 1990), ahora por la extraña decisión de los editores de volver sobre la príncipe. También la muy meritoria Tesis Doctoral de David O. Korn, en la que trata de arrojar luz sobre la compleja transmisión textual de la poesía de Mendoza basándose en el estudio de 22 sonetos, elude el tratamiento o la selección de los burlescos, porque están menos documentados y dan menos juego en el trazado de relaciones, aunque el resultado para el lector es de nuevo la preterición (Díez 2011).

No es la recuperación de Mendoza ajena a la que, tras la muerte del último dictador en 1975, sacude los estudios literarios (Díez 2003: 325-336). Dos décadas después, la colección Erótica Hispánica, puesta en pie con su generosidad habitual por José Lara Garrido, supuso uno de los hitos más interesantes en los estudios de literatura erótica española. La publicación al mismo tiempo de los tres volúmenes de la colección abría un prometedor camino para los textos eróticos de las tres grandes épocas en que suele dividirse la historia literaria española: La Carajicomedia — publicada en 1519 pero deudora de la tradición medieval (Alonso 1995)—, la Poesía erótica de Diego Hurtado de Mendoza y el Arte de putear, de Nicolás Fernández de Moratín. En cuidadas y novedosas ediciones, los tres volúmenes comenzaban un dibujo textual en una época dominada por la gaseosa teórica y ofrecían un testimonio contundente sobre la riqueza e intensidad de la erótica hispánica.

Por otro lado, la transmisión manuscrita se muestra, como era de esperar, mucho más libre y desde siempre acoge en su seno los textos serios y los otros, a menudo mezclándolos, quizá con despreocupación, quizá como sistema habitual en una copia de textos que no estará sujeta a revisión censora. Mucho interés tiene el ms. 2805 de la Biblioteca de Palacio de Madrid, descrito por DiFranco, Labrador y Bernard. Su interés no solo se debe, como indican los tres investigadores, a que es ligeramente anterior a la princeps, sino que se justifica también por el uso de marcas y comentarios posiblemente de uno de sus poseedores. Como las demás fuentes primarias de la poesía de Mendoza, ${ }^{19}$ excepto la edición de Hidalgo, el manuscrito recoge diversos poemas eróticos (la cana, la zanahoria y algunos sonetos, pero no la pulga). El poseedor-anotador se detiene muy en particular en la zanahoria, el texto

18. «En otras ocasiones la musa satírica de Mendoza aligera mucho más el freno que la comprime y se entrega a las burlas con todo desenfado, especialmente en obras de corte menor, que las hay ingeniosísimas. Las poesías de este tono no carecen nunca de valor anecdótico, y a menudo, a semejanza de tantas otras que son de vena cómica, conservan su gracia y regocijo a través de todas las edades [...] Por ser a veces muy cargada de especies [sic] no deleita por igual en toda clase de paladares. Por eso hemos echado mano de las menos fuertes, entre las cuales las hay muy apreciables como» los sonetos «Demócrates, deléitate y bebamos» $\mathrm{y}$ "En es el propio tiempo de emplearse» (Hurtado de Mendoza 1944: xlv). Incluye en la lista las coplas de Leyva y la contestación, «Ser vieja y arrebolarse» (que aparece en Hidalgo) y tres sonetos (los dos citados y «Esta piedra-puñal derrama-seso»).

19. «Ariadna sin hilo: una laberíntica transmisión textual» (Hurtado de Mendoza 2007: lxi-lxxxvii). 
en el que más escribe (y que solo se titula "Al duque de Sesa»). Así los ocho versos iniciales aparecen subrayados y anotados con "toda esta carta es malísima». La misma mano explica al final que «esta carta no se puede leer porque es sucísima». Sin embargo el mismo ojo y mano críticos no han objetado nada a otros poemas, como "Quien de tantos burdeles ha escapado", que además de tratar de la prostitución contiene alguna imagen religiosa de esas que el espíritu censor no suele dejar de percibir. También se le van sin comentarios ni marcas «El bombodombón», la cana, "Demócrates deléitate y bebamos», "Oh, Venus, alcahueta y hechicera» $\mathrm{y}$ "A vos la cazadora gorda y flaca», textos netamente eróticos. ${ }^{20}$ Sí señala, sin embargo, «Dicen que dijo un sabio muy prudente», pues el paso del juego literario de alusiones y dobles sentidos aquí se concreta en la denotación (que algunos llaman obscenidad) con un final ante el que no se pueden cerrar los ojos: «mira el ojo del culo, que es el centro, / y si árbol no tuviere me señora, / hallarasle dos centros en el rabo». ${ }^{21}$ Ese contraste entre un sentido exigente y una visión laxa más la inclusión de textos que no escaparon al vigilante cuidado de Hidalgo puede explicarse ahora porque no se trata de un libro destinado al consumo general que impone la imprenta o porque

el copista compone un manuscrito de la poesía de Mendoza sin atender a razones morales; el lector-poseedor no pasea sus ojos con la misma atención por todos los textos o, si lo hace, no se molesta en anotar sistemáticamente. Resulta más complicado acudir a un concepto diferente de gustos y rechazos, aunque también sería posible: mientras el editor de la princeps selecciona los textos, el lector del códice se preocupa más por la ortodoxia religiosa y se muestra mucho más permisivo en materia erótica. (Díez 2007: 110-111)

Pero si la edición de textos comprometidos y peligrosos que podían llevar al impresor a graves penas explica su ausencia hasta que el rigor positivista activa la recuperación filológica, el estudio de esos mismos textos quizá ha tropezado aún con más problemas, como la ausencia de prestigio de unos poemas que pueden conectarse con lo vulgar, con lo zafio, con lo antiestético. La miopía tarda en corregirse y, en una broma del destino, hay que esperar hasta la más inmediata posguerra para que dos investigadores en su magnum opus estudien con naturalidad todos los textos de Mendoza. El monumental hito de González Palencia y Mele supone la dignificación total en ¡1941-1943! El enorme trabajo sigue siendo una referencia imprescindible para el estudio de todo Mendoza y también para el de la poesía burlesca. ${ }^{22}$ Los dos primeros volúmenes desgranan con mucho cuidado y

20. Véase, infra, la nota 32.

21. Hurtado de Mendoza (2007: 148); para el empleo de «culo» en la correspondencia de Mendoza véase Varo Zafra (2011: 61-62).

22. Puede sorprender que la monografía de Darst no dedique un apartado a esta producción. Con todo, se encuentran medidos comentarios sobre la pulga, la zanahoria, la cana, el cuerno, el cangrejo y un soneto (27-29) y también sobre "A Venus» (44-45). 
de manera extraordinariamente documentada la vida de don Diego y junto con la monografía de Spivakovsky son de consulta indispensable. El tercer tomo dedica una parte al estudio literario, aunque permite un crecimiento importante de la crítica de la obra de don Diego, tanto en su poesía como en su prosa. Con todo, los dos autores dejan muy claro el dinamismo creador de Mendoza en la exploración métrica, en el desarrollo de los distintos códigos, en la imitación clásica y su renovación, ${ }^{23}$ en la asimilación y superación de las referencias y modelos italianos, etc., características que son también muy visibles en su producción burlesca (de la que se ocupan antes de abordar la «Fábula de Hipomenes y Atalanta»). El ingenio de este particularmente dotado vir doctus et facetus, que montaba redes de espías en el imperio turco al tiempo que coleccionaba manuscritos, que escribía y leía y que revoluciona la práctica burlesca y la erótica en particular al firmar sus textos (como reconoce el nada cándido editor de la princeps, frente a una divulgación mucho más frecuentemente anónima,), ese ingenio, decía, es muy evidente. Comparar a Mendoza en este cultivo con sus coetáneos (Boscán, Garcilaso, Acuña y Cetina, por ejemplo) refuerza la imagen de un don Diego muy inquieto (quizá seguido más de cerca por un Gutierre de Cetina y por ello fuente de conflicto en las atribuciones, como discutiré enseguida) y explorar sus intereses bibliográficos y científicos señala a una riquísima variedad de dedicaciones. ${ }^{24}$ Pero también Castillejo es un coetáneo (última década del s. Xv-1550), lo que a veces se olvida, y Mendoza es un decidido cultivador del octosílabo. ¿№ recoge Mendoza junto a la tradición italiana (con los matices que luego trato) las peculiaridades de la tradición «castellana» y de la cultura popular?25 Castillejo también cultiva el erotismo (Castillejo 1986 y 2014; Alonso 2006 y 2010; Garrote 2012), de procedencia clásica, italiana y castellana, en

23. Mendoza suele practicar en sus textos una imitación compuesta y personal (son «pues acertadas las intuiciones de Rothberg cuando sugería que Hurtado leyó varias versiones de un epigrama antes de crear el suyo», Ureña Bracero 1999: 327).

24. "Cardano recoge una lista de obras inéditas guardadas en la biblioteca de Mendoza» con textos de medicina y matemáticas, ingeniería y ciencias naturales, historia y gramática, música y astronomía (Socas Gavilán 2007: 431). Las innovaciones de Mendoza, que se anticipa a Cardano, en relación con la Mecánica de Aristóteles prueban «su relación con los círculos científicos de la época» (Iommi Echeverría 2011: 192).

25. «Adviértase que la equivalencia entre carne y miembro viril ha gozado de una vida larguísima ya desde la literatura medieval [...] Dentro del ámbito de lo popular, es posible señalar numerosísimas imágenes y metáforas (algunas de las cuales acaban asumiendo un valor simbólico) que nacen del seno de la cultura material. A él pertenecen las consolidadas referencias al mundo de la molienda, con lo que molino, molineros y molineras son protagonistas nada inocentes de un sinnúmero de relatos procaces» (Sepúlveda 2007: 62 y 64). "A diferencia de la lectura casi unívoca, por condición de sentimiento, de Garcilaso, la extensa e intensa vida renacentista de Hurtado de Mendoza le permite [...] un acudir tanto al pasado clásico como a la transmisión popular [...] El epigrama es interesante porque, como en las redondillas, villancicos o cartas, nos manifiesta (distintamente a Boscán) a un Mendoza que está transfiriendo temas de la cultura clásica (de Ovidio o Marcial) a las coplas castellanas, junto a la tradición española [...] y siguiendo una pauta italiana más o menos popular» (Prieto 1984: 94 y 101). 
octosílabos. ${ }^{26}$ ¿Hay una tradición burlesca y erótica castellana que los renovadores del octosílabo, Castillejo y Mendoza, también renuevan? ¿Le sirven a Mendoza la burla y el erotismo como conseguido intento de rebajar el sentido elevado del terceto, en la tradición bernesca? Sin duda así ocurre en la zanahoria y en la pulga, inversiones paródicas de modelos elevados. Pero ¿qué sucede con la cana? ¿Hay que rebajar el octosílabo también? ¿Es un caso de mera contaminación?

\section{La fijación del corpus para «poder vivir medianamente»}

La categoría "poesía erótica» no es tan evidente como el marbete tradicional de "poesía satírico-burlesca», constructo al que se sigue buscando una separación clara. Sin embargo, a pesar de su inclusión dentro de las burlas, la poesía erótica no encaja en ella ni tan automática ni tan herméticamente, ${ }^{27}$ aunque eso no evita la filiación risible de muchos de estos textos, a veces en una línea muy ciceroniana. ${ }^{28}$ En los poemas de Mendoza, como en los de otras tradiciones (en las que Mendoza bebe, como la de Berni y sus seguidores, por ejemplo), ${ }^{29}$ la risa y el erotismo parecen ir dirigidos primordialmente contra la tradición literaria seria y amatoria, si bien es mucho más difícil valorar el alcance social o en la vida diaria de esa burla, pues, entre otras razones, los límites entre literatura y realidad son de hecho necesariamente complejos. Me parece por ello más útil e importante volver sobre la relación de la poesía de Mendoza con la de sus contemporáneos: Garcilaso, ${ }^{30}$ Boscán y otros petrarquistas, pero también Castillejo. La poesía burlesca, y la erótica en concreto, suele considerarse más realista, menos estereotipada que otras modalidades (como el petrarquismo) y por supuesto da una visión insólita dentro de los rígidos límites dominantes en la literatura del Renacimiento. Más allá, y más acá de parodias y rupturas de tradiciones literarias específicas está el horizonte

26. «Considero la imagen que de la mujer nos ofrece Castillejo en su Sermón [de 1542] mucho más cercana a la cultura cómica popular y a la tradición gala, de la que Rabelais fue el más ilustre representante en el Renacimiento» (Beccaria Lago 1997: 419; para la influencia de Ovidio véanse 422 y ss.). Por su parte Periñán y Reyes recuerdan la relación de Castillejo con el Aretino e insisten en el magisterio de Ovidio en una obra que consideran de un «erotismo desbordado» (Castillejo 2014: 45 y 48). 27. Lo erótico, según Jammes, es una de las «cinco categorías de lo bajo: lo disparatado, lo descompuesto, lo escatológico, lo picaresco y lo erótico» (Arellano 2006: 352).

28. Cicerón señala que la risa funciona "como mecanismo para captar la atención del oyente» (Arellano 2006: 352). Y Castiglione opinaba que «solamente nos reímos de aquellas cosas que en sí desconvienen y parece que están mal, peo realmente no lo están» (Varo Zafra 2011: 60).

29. «De Berni y los poetas bernescos derivó sus capítulos y sus sonetos burlescos Mendoza, que fue el primero en introducirlos en la poesía castellana» (González Palencia-Mele, 1941-1943: III 102). «Mendoza brings to Spanish soil the insolence and the violence that had largely characterized the Italian burlesque tradition since the fourteenth century» (Martín 1991: 51).

30. « [...] la gran modernidad de Hurtado de Mendoza, respecto a Boscán y Garcilaso, radica en que el poeta granadino percibe lo que el renacimiento es, desde la forma del diálogo, un movimiento cultural que fecunda su parcela literaria en la innovación clásica que proporciona la fusión o mezcla de géneros» (Prieto 1984: 93). Sobre Garcilaso y el erotismo: Díez (2012). 
más amplio de la quiebra de los límites literarios y poéticos, que condenan a la exclusión temas y palabras: con frecuencia resulta determinante la selección de algunas palabras y su repetición, sobre todo cuando son palabras prohibidas. ${ }^{31}$ No se puede dejar de valorar tampoco que el juego crea una complicidad con el lector y supone un desafío a los otros poetas. De hecho los poemas eróticos de cierta extensión buscan desarrollar un tema prohibido de manera ingeniosa, en un auténtico tour de force, al cantar lo que no está permitido cantar o es complicado hacerlo. Buenos ejemplos son la zanahoria, la cana y la pulga, al moverse dentro del equívoco (en cana y zanahoria) y en la reticencia y la sugerencia (en los tres casos).

Si frey Juan Díaz Hidalgo, con evidente astucia, parece no poder menos que reconocer esa fama en Mendoza que apuntalan los tres poemas y que su edición pretende tapar, muy lejos de las labores de otros editores de poetas de los Siglos de Oro, el rechazo de esa producción y la corta nómina de los textos mencionados crea el problema del contorno del corpus, hasta ahora sin una solución completamente satisfactoria. Como en otros poetas de la época, con poesía burlesca o sin ella, el principal problema probablemente es la fijación de un corpus estable y seguro. Por eso mis ensayos anteriores a Hurtado de Mendoza (2007) (de 1989 y 1995) expresamente «deben considerarse, a partir de ahora, subsumidos - y superados- por esta edición» (xci), que pone al día las atribuciones y divide los poemas de Mendoza en dos grandes grupos: la poesía $\mathrm{y}$ los poemas atribuidos.

El corpus erótico se puede clasificar atendiendo al género y a los temas en distintos apartados (algunas historias, seres y objetos admirables, tres mujeres, puterías y alcahueterías, los cuernos y un cómodo cajón de sastre: Hurtado de Mendoza 1995: 32) que aún pueden variar (parodias petrarquistas, encomios paradójicos, narraciones, burlas de dioses y héroes, sátiras y versiones: Díez 2003: 97-98), pero también se pueden (y se deben) organizar los treinta y un poemas que componían la Poesía erótica (subtitulada inicialmente Poesía erótica: original, traducida, atribuida), según la certeza en la atribución, en los poemas que componen el núcleo muy duro de la producción de Mendoza ${ }^{32}$ y sumarse a ellos los poemas atribuidos una (los hápax) o dos veces solamente, ${ }^{33}$ separados de los minoritarios de atribución compleja e improbablemente debidos a la pluma

31. «Mendoza's artistry in both of these sonnets lies in his use of witty euphemisms. Crude expressions, whether sexual or scatological, produce an entirely different effect» (Martín 1991: 46). Véase Díez (2015).

32. "A la pulga» (5-13), "A la zanahoria» (22-26), "Quien de tantos burdeles ha escapado» (143), "OOh Venus, alcahueta y hechicera,» (146-147), «Dicen que dijo un sabio muy prudente» (148149), «Cortada sea la mano que te diere» (150), «Éste es el propio tiempo de mudarse,» (151), «De Penélope» (152-153), «Hay una, quien quisiere saber de ella» (158-166), «En loor del cuerno» (167-175), «A vos, la cazadora gorda y flaca,» (226-227), «El bombodombón» (320-323), «A Venus» (339), «A una señora que le envió una cana» (346-349), «Octavas al cangrejo» (387-392), «Consejos» (393-395), «A una dama entonada» (396-400) y «A las damas de palacio» (406-412). 33. «Preciábase una dama de parlera» (471) y "A manera de matraca» (477-482). 
de Mendoza. ${ }^{34}$ Quedan excluidos los poemas que no son de Mendoza ${ }^{35}$ y que por eso, de manera más que obvia, deben desaparecer como objeto de estudio de la poesía de don Diego.

La fijación del corpus es necesaria por la lógica necesidad de leer solo lo que el poeta ha escrito y no lo que la tradición crítica le ha ido prohijando con mayor o menor acierto; es, también de manera muy evidente, uno de los grandes objetivos de la filología. Un corpus estable y aceptado permitiría aplicar las nuevas técnicas digitales para intentar dilucidar atribuciones a partir del uso del vocabulario y de estilemas, y no solo en la obra poética. ${ }^{36}$ Así los siete poemas eróticos atribuidos a Mendoza y a otros autores (Juan Farfán, Gutierre de Cetina, fray Melchor de la Serna, Juan de Almeida y Gregorio Silvestre) podrían encontrar una paternidad segura. No hay que descartar posibles conflictos entre la vieja filología y las nuevas tecnologías, aunque, cuando se produzcan, habrá que establecer ciertos protocolos. Por otro lado, quienes no confían en la sola bondad de la crítica textual que falla sin ninguna duda que el autor del soneto " $i$ Oh Venus, alcahueta y hechicera," es Hurtado de Mendoza (2007: 146-147) y no fray Melchor de la Serna, ${ }^{37}$ podrán obtener una información de la que careció el compilador o compiladores del ms. 354 de la Biblioteca Nacional de Florencia cuando, ante la duda, decidió copiar el soneto dos veces para poder atribuirlo a cada uno de los posibles creadores. Un caso semejante se da en el "cancionero sevillano de Toledo», del que me ocupo enseguida, cuando al seńalar el autor de un texto más largo (y que por eso quizá no copia dos veces) no logra decidirse entre Hurtado de Mendoza y Acuña. Sin embargo, otra es la circunstancia de «A la pulga».

\section{Una pulga que crece y se desliza: en busca del padre}

Para cualquiera familiarizado con las fuentes de la poesía de los Siglos de Oro no es ninguna sorpresa el carácter difuso y a menudo equivocado que los manuscritos ofrecen en materia de atribuciones. El establecimiento de una paternidad, si no

34. «¡Oh, carnero muy manso! ¡Oh buey hermoso,» (568), «Pues en el golfo grande de la cola» (582-301), «Señora, la del arco y la saetas,» (594), «No hay cosa más gastada ni raída» (601), «Ella, la bien casada y mal contenta,» (627), «No me tengáis por hombre sin gobierno» (631) y «Compadre, el que de sabio más se precia» (635-642). Dos de los poemas han sido editados en las Rimas de Cetina, por Jesús Ponce («Pues en el golfo grande de la cola», 1024-1049, y «Compadre, el que de cuerdo más se precia», 969-983).

35. «Dentro de un santo templo, un hombre honrado», «Haced, Amor, que el mar jamás se mueva», «Hacía calor y en punto a mediodía» y "¿Qué hacéis, señora? - Mírome al espejo» (véanse los «Poemas de atribución errónea [y 2]» en Hurtado de Mendoza 2007: 673-678).

36. Varo Zafra (2011: 99-147). Más sobre «el abrupto carácter del granadino», su «habitual soccarronería» e ironía, el "tono jocoso» de su epistolario, "el habla sin afectación» y su carácter «lenguaraz» en Varo Zafra (2011: 22, 37 y 59).

37. Particularmente útil para acercarse al misterioso poeta es la parte monográfica del número de Canente (Martín y Díez 2003) y las ediciones de Zorita et al. (1991) y Labrador et al. (2001). 
responsable al menos segura, proviene de delicados factores y si una golondrina no hace verano y ni siquiera una cana es señal de vejez, una única atribución suele despertar, en muchos casos, una sospecha que habría que considerar tan prudente como acertada. No solo ocurre con los manuscritos, pues la imprenta en los Siglos de Oro se mueve entre suposiciones a menudo apoyadas en testimonios manuscritos para establecer la paternidad de los textos. Solamente los autógrafos o los testimonios que hayan sido revisados por el autor ofrecen garantías difíciles de contestar. Por eso, hacer descansar sobre el manuscrito 506 de la Biblioteca de CastillaLa Mancha - un viejo conocido de los investigadores de la poesía de los Siglos de Oro- , rebautizado como "cancionero sevillano de Toledo", la responsabilidad de dirimir un antiguo conflicto de autoría en torno a un célebre poema sobre la pulga parece, en principio, arriesgado. El texto se encuentra ahora más a disposición que nunca de los lectores gracias a los buenos oficios de la Universidad de Sevilla y al duro trabajo de los editores del volumen (Labrador, DiFranco y Montero 2006).

Primero los editores, con la prudencia necesaria, adelantan que "la cuestión no puede darse por zanjada en modo alguno» (34). Poco después, sin embargo, cuando se discute la atribución de «La pulga» en un todo formado por tres poemas (la cola, la pulga y la necia) hay «sólidos argumentos textuales» a favor de Cetina, ${ }^{38}$ pues el manuscrito

ofrece en esta parte una colección de poemas de Cetina hecha con materiales de primera calidad, seguramente porque la recopilación se hizo en Sevilla y en años muy próximos a la presencia del poeta en la ciudad. Es probable que las atribuciones a Mendoza, que son algo más tardías, puedan explicarse porque la fama de don Diego como poeta satírico sirvió ańos más tarde de polo de atracción para adjudicarle piezas de ese tono cuya autoría se había vuelto borrosa con el paso del tiempo (34).

La oscura biografía de Cetina no permite en ningún caso asegurar que la mano del poeta tuvo alguna participación en la composición del cancionero y los editores están muy lejos de afirmarlo. Sin embargo se valen de «la presencia del poeta en la ciudad» cuando el cartapacio se forma, y aquí quizá convendría ser mucho más cautos, pues Cetina, que se mueve por diversas cortes italianas entre 1538 y 1548 (con un viaje a Nueva España hacia 1546), parece que entre 1549 y 1552 sí estuvo en las tierras "que su familia poseía en la villa hispalense de Alanís», que realizó un segundo viaje a México en 1552-53, y que murió entre 1554 y 1557 también en México (Cetina 2014: 18-28 y 35). En principio el cancionero fue «confeccionado con toda seguridad en Sevilla, entre 1560 y 1570» (Labrador Herraiz et al. 2006: 17), aunque luego queda más claro que la seguridad es del lugar, no de las fechas: «Todo esto nos lleva a concluir que la recopilación del códice pudo concluirse h. 1560-1570» (28).

38. Cinco años después, sin más argumentos, dos de los editores han alcanzado la certeza: «pensamos que este poema es sin lugar a dudas del vate sevillano» (Labrador-DiFranco 2011a: 113). 
El manuscrito copia toda una sección de Miguel Garijo o Guarijo, quizá sevillano según los editores y que es «un caso interesante de poeta malo» (34). El códice incluye otros poetas desconocidos como Antonio de Pineda (cinco poemas), Bartolomé de Casas (dos) y Francisco de Venegas (uno). Como ya he indicado, el texto «Siéntome a las riberas destos ríos» se copia dos veces y se prohíja a dos autores distintos, en el cuerpo y el índice (35) y lo que podría ser una virtud («es de señalar que la nuestra es la única fuente conocida del xvi que propone una autoría para este poema, mientras que las demás lo copian como anónimo») es también un problema. Desde luego no seré yo quien critique a una suerte de colega que atribuye mal un poema a Mendoza y que intenta corregirlo sin lograrlo del todo, pero lo que sí me pregunto es de dónde copia el recolector, cuáles son sus fuentes y qué valor tiene su compilación.

El principal interés del manuscrito sevillano de Toledo es su supuesta temprana fecha y la importancia que tiene en la escasa transmisión de la poesía de Cetina (Rico García 2009), pues toda la sección segunda está dedicada a él. ¿¿De aquí se infiere la intervención del poeta o de alguien próximo? El compilador, sevillano y con una conexión con Cetina o su entorno, según parecen sugerir de manera mucho más prudente los editores, no identifica a pesar de todo un soneto de Cetina que copia luego, el 144. Además, para un sevillano o alguien que colecciona los textos en Sevilla resulta interesante la copia de textos de Juan de Vadillo, pero resulta perturbador que no se incluya el soneto de Vadillo a la muerte de Cetina o que una canción se atribuya doblemente a Cetina y a Vadillo (40). Entre la gran cantidad de hápax (que pueden indicar un contacto muy especial con el autor o una importante metedura de pata) se cuentan cuatro sonetos de Vadillo y cinco de Terrazas (que para los editores «seguramente son indicio de la presencia del poeta en Espańa, más que de un trasiego de papeles entre las colonias y la metrópoli», 36), aunque las sorpresas continúan, pues «las principales fuentes de conocimiento para la lírica de ambos [Vadillo y Terrazas] son nuestro códice y MN 2973 [...], pero se da la circunstancia llamativa de que esos dos cancioneros no comparten ninguna de las composiciones de uno y otro ingenio». ${ }^{39}$ En el caso de Cetina, ex-

39. Labrador Herraiz et al. (2006: 37). Las Flores de varia poesía se compilaron en México poco después de la muerte de don Diego, pero nadie ha supuesto una estancia de Mendoza en América ni un contacto directo con el manuscrito. Aunque muere veinte años antes, ese enlace quizá es Cetina, como propone la moderna editora (Peña 1980: 51-52; yerra en considerar a Antonio Hurtado de Mendoza, el autor de uno de los sonetos preliminares de la edición de Hidalgo, hermano del poeta; por eso los poemas de don Diego habrían llegado a México a través de Gutierre de Cetina). Los dos, junto con Cuevas, son los más representados en el códice. Por supuesto, «A la pulga» no se copia (ni la cola, ni la necia). En mi hipótesis sobre la transmisión de la poesía de Mendoza (Hurtado de Mendoza 2007: lxxv) hay dos tradiciones y en la más antigua, que es la «que circula menos», estarían, entre otros testimonios, las Flores. Junto al dato objetivo (no siempre fácil de establecer) sobre cuándo se copia un manuscrito hay que tener en cuenta (y eso es aún más difícil, pero a veces es posible saberlo) la tradición que copia un códice. Así mi texto base para la edición de Mendoza es del s. xvir pero tiene un nexo innegable con el autógrafo, que es de mediados del s. XvI. 
plica Ponce Cárdenas, «la relevancia de este códice es máxima, ya que se trata del único testimonio que ha transmitido el epilio de la Historia de Psique y Cupido, el conjunto de los poemas en octosílabos, un curioso madrigal en voz de una monja y cuatro sonetos no recogidos por ninguna otra fuente» (Cetina 2014: 171).

No me detendré en la importancia que tiene y en los problemas que crea el ms. 506 para la poesía de Mendoza, pero sí señalaré un único detalle. En «A Venus» (Labrador Herraiz et al. 2006: 339) el códice desarrolla el título de manera inusual y quizá muy imaginativa o provechosa: "A la condesa de Lerma, estando vestida con un coleto de gamuza y su daga y escarcela y una gorra con sus plumas», que se repite únicamente y de forma abreviada en otro testimonio, el cancionero de 1628 ("A la condesa de Lerma con capa y gorra»), con el que el sevillano-toledano parece tener vínculos. ${ }^{40}$

"A la pulga» aparece copiada en el manuscrito sevillano de Toledo en medio de dos poemas burlescos por lo que puede haberse producido un caso de atracción, aunque no en la dirección que anotan los tres editores para alejar el ascua de Mendoza. A la «Epístola a un compadre. Trata del amor de la nescia y hermosa, y el de la fea y sabia» (Labrador Herraiz et al. 2006: 155-161), le siguen la "Epístola a un compadre. Trata de una pulga» (162-168) y la "[Epístola]» sobre la cola ${ }^{41}(168)$. Crear una serie de tres epístolas de género burlón crea a su vez el preciso contexto homogéneo para la asimilación. Es más. Frente a otras versiones "A la pulga" aquí también empieza directamente con un "Compadre», como la necia («Compadre, el que de cuerdo más se precia»), un barrunto más que señala a la asimilación. Mendoza es autor de un poema en "Loor del cuerno» y a Cetina se le atribuye una composición en prosa sobre el cuerno. En este caso las diferencias de cauce evitan la atracción en dos textos que abordan un tema común, ${ }^{42}$ sin embargo en "A la pulga» un encaje tipo sándwich puede manifestar la fuerza del arrastre.

Por otro lado, hay que constatar que no parece haber cosechado Cetina apoyos que vayan más allá de los de sus editores, mientras Mendoza, en un limitado tour, sí allega alguno, como este de Antonio Prieto para suponerle autor de "A la pulga»

40. El ms. 1578 BPM, manuscrito primario para Mendoza, copia la cola y la necia seguidas y las atribuye a Cetina (ff. 139-153v.) y justo a continuación incluye la zanahoria, de Mendoza (también el Cancionero de 1628 copia ambas [cola y necia], aunque no una junto a otra, y las atribuye a Cetina). El argumento que se vale de que el manuscrito de la Biblioteca de Palacio es importante para Mendoza es de doble filo, pues el mismo códice copia "A la pulga» entre los poemas de don Diego. En el ms. 1578 BPM la necia tiene 236 versos (faltan «y morirá primero que perdella. // La otra, que en rezar su vida gasta», vv. 78-79).

41. Puede parecer que algunos compiladores derrochan imaginación como ocurre con el ms. 143/86 de la Bancroft Library, en la Universidad de California en Berkeley, que lo titula «Carta de don Diego de Mendoza a don Bernardino, su hermano»; pero este título sí se corresponde con otro texto de Mendoza: «llustre capitán victorïoso» (Hurtado de Mendoza 2007: 57-62).

42. La obra de Mendoza posee «evidentes concomitancias temáticas con la de Cetina» (Núñez Rivera 1998: 1137). 
«porque pertenece a un ámbito desmitificador, en ocasiones detenido en lo cotidiano o argumentos triviales, que pertenece a una situación bernesca vivida por Mendoza» (101), u otro de Valentín Núñez. ${ }^{43}$ Como dato curioso simplemente, hay que recordar que don Diego está en Venecia ${ }^{44}$ de 1539 a 1546 (y en Italia hasta 1552), pero ¿y Cetina? Su errar por diversas cortes italianas en una cronología semejante no parece haberle llevado a Venecia, aunque sí a Nueva Espańa, como ya he indicado, lo cual aunque no sería obstáculo insalvable para que pudiera estar familiarizado con "una veneciana fantasía», señalaría que Mendoza la habría tenido mucho más a mano. Sin embargo la circulación manuscrita en las cortes italianas pudo poner al alcance de Cetina no solo los poemas de Tansillo (Ponce Cárdenas 2012: \$29-30). Por otro lado también Delpech utiliza como argumento de apoyo a la autoría de don Diego de las «Octavas al cangrejo» precisamente su estancia en la República (1993: 45). "A la pulga» es mencionada por Hidalgo en su prólogo, como se ha visto, y por Lope de Vega, que considera que el poema está muy extendido y es famoso, ${ }^{45}$ pero la pista de la única atribución a Cetina, en el manuscrito sevillano de Toledo, se pierde hasta que en el siglo XIx la recupera Bartolomé José Gallardo, y con problemas textuales como explico enseguida. No sorprende que, además, en la rica tradición manuscrita de la poesía de Mendoza hasta nueve fuentes primarias recojan el poema y no sorprende tampoco que una de ellas particularmente privilegiada decida abrir precisamente con este texto.

Pero sin duda lo más llamativo de esta autoría compartida es que la versión que copia el cancionero sevillano de Toledo sea la más larga de todas las conservadas, con 253 versos, muy lejos de los 223 o 226 que tienen las versiones que la prohíjan a Mendoza. ¿Más es mejor? No siempre. De hecho los añadidos podrían ser, como creo, amplificaciones de un autor desconocido, un segundo autor. No es infrecuente ese tipo de amplificaciones en los textos burlescos de Mendoza, como estudio más abajo. Incluso otros manuscritos que copian el poema no solo lo atribuyen a Mendoza sino que coinciden en el número de versos con las fuentes primarias, ${ }^{46}$ lo que parece incidir en la amplificación del sevillano de Toledo, como lo confirma el estudio de los versos.

43. «No sabemos si la pulga pertenece con seguridad a Hurtado, a lo cual, yo personalmente me inclino, pero se cuenta con razón entre uno de sus poemas más célebres» (Núñez Rivera 1997: 116). 44. "The library had been predominantly formed during the ambassador's six years in Venice» (Hobson 1999: 91). Las ediciones de Ariosto, Berni, Franco y Aretino con que cuenta su biblioteca son precisamente venecianas.

45. «Dïocles puso en alabar el nabo, / materia apenas para un vil esclavo; / el rábano Marción, Fanias la ortiga, / y la pulga don Diego de Mendoza, / que tanta fama justamente goza» (Vega 1969: 1486). Que Mosquera de Figueroa no recoja la pulga en su enumeración, que sí allega ejemplos de la antigüedad (la calva, el nabo, la cigarra, la berza, la mosca, la nuez, etc.), y que sí menciona la zanahoria de Mendoza y la cola de Cetina (Núnez Rivera 1998: 1140-1141), puede deberse al carácter selectivo que atribuye a cada autor un solo texto.

46. 3670 BNM ff. 151-155: 223 vv.; 3909 BNM ff. 295-303: 226 vv.; 62 Seminario de Vitoria ff. 131-34v: $226 \mathrm{vv.}$ 
La primera amplificación se produce tras el verso 63 y consta de cinco estrofas. Antes de leer los versos y comprobar que contienen un ataque salvajemente anticlerical hay que constatar cómo en la última estrofa añadida el excurso retorna al tema principal: «Tornémonos, compadre, a nuestra historia; / tornemos a la pulga, a sus denuedos; / los frailes lleve Dios presto a su gloria». ${ }^{47}$ No solo la repetición del verbo «tornar» sirve para «anudar» el retorno de la digresión, como indica Ponce, sino que sirve también para incidir en los problemas compositivos de una amplificación. Para insertarla el anónimo poeta debe transformar la estrofa previa («Aquéllos son bocados más sabrosos, / allí me las den todas tus denuedos, / allí puedes hacer tiros donosos»): «Aquellos son bocados más sabrosos: / para tu condición, que también ellos / son de nueva sangre cudiciosos» (Cetina, vv. 61-63). Lo más importante es que el tono de la digresión desdice del juego sutil y divertido que compone todo el poema "A la pulga", pues con la descripción de un fraile que bebe la sangre menstrual el anónimo amplificador exhibe su poderoso y subido músculo poético, seguramente porque sabe que el resultado está destinado a un manuscrito:

Tanto que vi una vez alguno de ellos atento en ver sangrar una doncella que en pensallo se me alzan los cabellos.

Estaba el fraile enamorado de ella y, por mostrar su amor, mirando el vaso de aquella sangre, arremetió a bebella. Pero yo soy un simple en campo raso, vos conocéis las partes y aún me acuerdo cuándo y dónde tratamos de este caso. En hablando de frailes luego pierdo el seso, la paciencia y la memoria: ¡mirad qué calidad de escritor cuerdo! (Cetina, vv. 64-75)

¿Es el autor el mismo compilador o se trata de alguno de los desconocidos poetas, probables amigos? ¿Qué sentido tiene prohijar la pieza a Cetina? No hay que descartar que la atribución se practique a sabiendas de que el poeta ha muerto hace varios años.

Antes del segundo excurso, con el que se cierra la pieza, se añaden algunas estrofas sueltas. Así tras el verso 81 de la versión de Mendoza hay una estrofa nueva. El texto ha sido sometido a una mínima pero determinante operación que permita enlazar con la nueva rima y por eso se ha modificado el verso 80 , que lee en todas las versiones "méteos en el celebro una tormenta" y que ahora se convierte en "méteos un armonía en la cabeza» (v. 95), con la consiguiente pérdida de sentido para explicar el efecto que produciría una pulga en el oído: «allí va

47. Cito siempre por la magnífica edición de Ponce Cárdenas, que tiene además la ventaja sobre Labrador et al. 2006 de modernizar el texto: 953, vv. 76-78. 
susurrando como abeja; / méteos en el celebro una tormenta / cual debéis ya saber, que es cosa vieja» (Hurtado de Mendoza, vv. 79-81). La nueva estrofa debe recuperar la "tormenta" anterior y lo hace de manera tosca: "¿Qué os diré del andar, si a andar empieza, / el pasear que trae y la tormenta, / sin que caiga jamás ni aun estropieza?» (Cetina, vv. 97-99).

La misma versión sevillano-toledana escribe el nombre de "Teresa» en dos ocasiones, una vez más frente a toda la tradición manuscrita, lo que indicaría posiblemente un aprovechamiento muy personal del texto. Así el verso 160 ("Dijérale: "Señora, yo he venido" ) se lee de otra manera: «Dijérale: “Teresa, yo he venido"” (Cetina, v. 178) y poco después se reitera curiosamente una nueva estrofa que varía de forma extraordinaria la unánimemente transmitida, pues de «Pero yo os voto a Dios, compadre hermano, / que, si la señoreta no callara, / que no fuera el dar voces lo más sana» se pasa a «Dar voces es indicio de liviano / seso. Teresa es cuerda, ella callara, / y al fin las buenas callan y es más sano» (Hurtado de Mendoza, vv. 184-186 y Cetina, vv. 202-204). No me detengo en otros cambios. ${ }^{48}$

La segunda amplificación es también de quince versos (o de dieciséis, para ser más exactos con respecto a las versiones breves) y muy significativamente es la que cierra el poema (vv. 238-253), pues los finales son lugares óptimos para la amplificatio. En este excurso al «compadre» del comienzo se le llama «señor» («Mas ved, señor», v. 241, que repite un esquema sintáctico) justo antes de retomar el trato inicial («entre tanto, compadre», v. 244):

puesto que ni tan grande o mayor prueba ni cuanto puede Amor, caso, ni suerte contra mi fe podrán que se remueva. Mas ved, señor, si es caso extraño y fuerte que siendo mi intención decir locuras, mi tristeza en tristezas las convierte. Entre tanto, compadre, estoy a escuras. Son las dos de la noche y no he podido salir de conjurar mis desventuras.

48. La estrofa «qué hiciera de torcerse y de quejarse! / Pues ¿quizá que dejara de picarla? / ¡Ni por verla llorar ni lamentarse!» (Hurtado de Mendoza, vv. 205-207) se transforma en «Hiciérala llorar y lamentarse / y sin haberla de picar dejado, / ni por verla dar bozes ni quejarse...» (Cetina, vv. 223-225), con más problemas. Falta, además, una estrofa en la versión auténticamente única del ms. 506 BCLM: «Hallarme por el rostro ni esperarla, / si viniera a tomarme, era excusado; / yo sé bien cómo había de molestarla» (Hurtado de Mendoza, vv. 208-210). Por otro lado la repetición de «Nembrot» como «Membrote» también es única en el 506, y aunque los demás manuscritos optan por uno u otro la mayoría prefiere el segundo. Ponce anota que en la Vulgata se lee "Memrod» (Cetina 2014: 966), por lo que me inclino a creer que la repetición más que un juego delata problemas de lectura: «Pintárale mayores mis tormentos / que la torre que el asno de Nembrote / o Membrote empezó sus fundamentos» (vv. 171-173), frente a la lectura mayoritaria: «Pintárale mayores mis tormentos / que la torre que el asno de Nembrot[e] / comenzó con tan vanos fundamentos» (Hurtado de Mendoza 2007, vv. 154-156). 
En la cama, do estoy, me he detenido con una pulga, que me hace a fuerza escribir todo cuanto habéis oído.

No me deja dormir, antes se esfuerza a picarme y está en diablo puesta allí donde Belona ha mayor fuerza: ¡ved cuánto es atrevida y deshonesta! (vv. 238-253)

Es verdad que la fuente italiana que reelabora el poema es mucho menos extensa que cualquiera de las versiones españolas, pero resulta significativo no tanto que ninguna de las dos amplificaciones esté en la fuente sino que en la versión castellana se vuelva inmediatamente a ella tras el primer excurso y, de manera muy especial, que justo antes de la estrofa añadida (vv. 97-99) y justo después de ella se retomen los versos del original italiano (Cetina 2014: 963).

Todo parece indicar que la versión del ms. 506 BCLM es única en más de un sentido: es la más larga, es la que incluye interpolaciones y es la única conservada que la atribuye a Cetina. Ni siquiera la versión que copia Gallardo (1863-1889: II 437-440) coincide con ella, versión que ha sido tomada «de los Opúsculos de varios ingenios sevillanos, recogidos por Matute. Ms. original», es decir, que procede del ms. 33-180 de la Biblioteca Arzobispal de Sevilla, hoy perdido. El texto tiene 219 versos y coincide con las versiones que lo atribuyen a Mendoza, excepto en esos tres versos que faltan: Gallardo lee «Dijérale: ‘ ¡Mi alma, entrañas, vida! / Yo me muero por vos mas ha de cuanto, / no dejemos pasar esta venida» donde los demás encuentran seis versos:

Dijérale: «Mi alma, entrañas, vida, mi corazón, redańos y asadura, y mi (¿cómo se dice?) y mi querida: vos estáis sola y, si queréis, a escuras; yo me muero por vos, mas jah, de cuánto!, no dejemos pasar estar venturas. (Hurtado de Mendoza, vv. 139-144)

Las fuentes se separan, todas, de la versión del manuscrito sevillano de Toledo, aunque manifiestan entre sí sus diferencias en el final del poema. Así algunas copian 222 versos y concluyen con un terceto; otras ańaden el cuarto verso al terceto de cierre («haciendo que a una parte y a otra tuerza», «sin que a otra ninguna parte tuerza»); otras, por último, insertan toda una cuarteta y alcanzan los 226 versos. ¿Se perdió el último verso? ¿Se evita la última estrofa por ser mucho más explícita que el resto del poema al señalar con precisión dónde está picando a quien habla? Es curioso que los manuscritos del Xviı sean los que ańadan esta cuarteta:

Entre tanto esta pulga anda y se esfuerza picándome y está en diablo puesta 
allí donde Bellona ha mayor fuerza

¡ved cuánto es atrevida y deshonesta!

Como el sevillano de Toledo, el ms. 3909 BNM lee «ballena», peor lectura desde luego y que Ponce Cárdenas corrige con acierto por «Belona». Si este es el cierre original entonces el segundo excurso no contaría más que con once versos. Con todo, lo que queda claro es que la versión del ms. 506 BCLM, que atribuye el poema a Cetina, presenta muchos más problemas que las coincidentes versiones de todas las demás fuentes.

\section{Más zanahorias: de la adaptación improbable a la creación}

La zanahoria es el primer nombre que acude a la pluma de frey Juan Díaz Hidalgo para trazar el mínimo elenco de los poemas rechazables y rechazados. No es extraño que fuera así pues el poema, de los tres mencionados en las Obras del insigne caballero don Diego de Mendoza, es el que más se documenta en los principales manuscritos y el editor que evita poemas burlescos no tiene dudas sobre la autoría de la «azanahoria, cana, pulga». La transmisión textual de los tres poemas es diversa, pero en el caso de los noventa y cuatro endecasílabos que componen la zanahoria hay que constatar que no han sufrido las variaciones que veces provoca una transmisión compleja o simplemente menos documentada, como ocurre con la cana (y lo desarrollo enseguida).

En esta ocasión Mendoza cuenta con una decisiva fuente de inspiración para elegir el tema, pero prefiere no traducirla, ni siquiera ampliarla (como sucede en la pulga), ni tampoco abreviarla. La zanahoria se sitúa en la órbita de Berni (que escribe «in lode della peste», «dell'anguille», «dell'orinale») y sus seguidores, ${ }^{49}$ y muy en especial porque uno de ellos, Mattio Franzesi, escribió dos capitoli al mismo tema, lo que no había escapado a la crítica. ${ }^{50}$ Pero los dos textos solo se publicaron cuando Mendoza no estaba en Venecia, ni siquiera en Italia. Los escasos datos sobre Franzesi no permiten muchas alegrías (Longhi 1983: 52) y no parece posible saber si Mendoza lo conoció o si pudo leer una versión manuscrita de los dos poemas, que pudieron haber salido de la pluma de Franzesi ya en 1534 (Cacho Casal 2006: 14). Mendoza menciona a veces sus fuentes, por elíptico que sea el sistema. Así en «A la pulga» remite a "cierta veneciana fantasía» para señalar la versión que amplifi-

49. «[...] este poema se suele adscribir a los capitoli burlescos que compuso Mendoza a imitación de la poesía bernesca (junto a "En loor del cuerno» y «A la pulga», entre otros), dentro de la poesía anti-petrarquista» (Aguirre de Cárcer-Díez 1994: 459).

50. Prieto 1984: 100. «Sopra le Carote. A M. Carlo Capponi: Vorrei potervi fare altro piacere»y «Sopra le medesime, al medesimo: Poich'io mi penso vi sia stato caro», en Il secondo libro dell'opere burlesche di M. Francesco Berni, del Molza, di M. Bino, di M. Lodovico Martelli, di Mattio Franzesi, dell'Aretino, e di diversi autori, Florencia: Bernardo Giunta, 1555 (Longui 1983: 249 y 268-270: enumera hasta treinta capitoli de Franzesi). 
ca, que no es otra que un poema de Ludovico Dolce, y en «El cuerno» se acuerda de Ariosto, «el cual es excelente autor moderno». No puede negarse que la zanahoria es «uno de los que más se asemejan a la manera del Berni y de los bernescos italianos» (González Palencia-Mele 1941-1943: III 103), pero la dificultad para encontrar un modelo obliga a decantarse por la técnica del collage en el texto de Mendoza, donde también halla su hueco una tradición médica que el embajador conocía muy bien. ${ }^{51}$ De hecho, en el detenido trabajo de Cacho Casal (2006) los contactos con los dos capitoli quedan reducidos a que la raíz calienta, es de dos colores y a algunas coincidencias en la preparación aunque «el catálogo de Mendoza resulta mucho más detallado y extenso» (17), pues hasta la forma ("rolliza y prolongada») debe buscarse en el Capitolo sopra la salsiccia (19). No puede contarse entre esas relaciones el aire epistolar de los tres poemas, pues es propio de los capitoli bernescos en general. ${ }^{52} \mathrm{El}$ elogio de la zanahoria no es exactamente paradójico en ninguno de los tres poemas, como suele ocurrir en los elogios de los alimentos, sino de doble sentido. ${ }^{53}$

Los 131 versos del primer poema de Franzesi y los 121 del segundo ${ }^{54}$ suman dos veces y media la cantidad de endecasílabos que Mendoza compone. Está claro que si don Diego conoció los dos capitoli optó por no seguirlos, aunque es posible que Mendoza compusiera su poema de forma independiente de Franzesi, dentro de la tradición de la escuela de Berni. También el cangrejo muestra una «incitación bernesca» (Prieto 1984: 104), así como el soneto de extenso estrambote (Lara Garrido 1997: 125; Martín 1991). A veces en la historia literaria no hay más remedio que partir de otro texto o incluso de una idea, ${ }^{55}$ pero en los temas eróticos no siempre hay que acudir al contagio textual directo: «El equívoco sexual conseguido mediante la comparación metafórica del pene con una serie de raíces que se le asemejan por sus características morfológicas (zanahoria, nabo, rábano) resulta frecuentísimo. Y por eso mismo casi todas esas verduras han sido objeto en algún momento de encarecimientos burlescos donde menudean las referencias fálicas» (Núñez Rivera 1997: 111).

Un indicio no solo de que el poema de Mendoza tiene una orientación distinta, sino de que realmente persigue otros fines, es la ausencia de la mentira en "A la zanahoria», frente al desarrollo de Franzesi a partir del sentido de "piantar carote». ${ }^{56}$ Es evidente que la lengua española carece de esa equivalencia, pero el

51. «[...] aportando imágenes e ideas derivadas de varias composiciones bernescas [...] el poema de Hurtado de Mendoza ofrece pues una summa del arte bernesco» (Cacho Casal 2006: 17 y 23). Aguirre de Cárcer-Díez.

52. "Il capitolo burlesco nel Cinquecento assume molto spesso la fisionomia di epistola» (Longhi 1983: 182).

53. «Vorrei potervi fare altro piacere, / messer Carlo, che dir delle carote / se non le lodi, almanco il mio parere» (Franzesi, I, vv. 1-3).

54. Que se justifica porque «ma la materia mi cresce tra mano» (v. 5).

55. El autor de la cola "pudo tomar la idea de Le lodi della coda que forma parte de las Satire de Giovanni Agostino Caccia» (Cacho Casal 2003: 482; la cursiva es mía).

56. Adonde ya se llega en el verso 35 del primer capitolo ("perchèll piantar carote or ha più spaccio»). 
poema de don Diego no se inclina hacia la sátira social, como los de Franzesi: «Mendoza se ha limitado a producir un efectivo juguete de ingenio que gira en torno a los dobles sentidos obscenos y a las agudezas que suscitan" (Cacho Casal 2006: 27), lo que puede ser tanto como alabar su coherencia... y quizá una prueba de que se persigue un objetivo diferente, no tanto o no solo porque la sociedad espańola no está cerca de la italiana del Renacimiento sino por un concepto más homogéneo del poema (que es aquí por eso sensiblemente más corto que sus homólogos). Llama mucho la atención que la zanahoria de Mendoza evite los dos grandes temas de Franzesi: la homosexualidad y la crítica social (muy dirigida contra los eclesiásticos). Es cierto que la permisividad de las dos sociedades hacia la homosexualidad no es la misma en el siglo xvi, pero también lo es que las bromas contra los sodomitas no están excluidas de la poesía española. Cabe creer que Mendoza las rehúye si leyó los dos poemas, pero también cabe incidir en un cultivo distinto de un tema, el de la zanahoria, al que se le puede sacar punta de otras formas. O quizá Mendoza, por decirlo de otro modo, empieza donde acaba Franzesi y escribe lo que sería un tercer capitolo.

La fecha de composición podría arrojar luz sobre una posible creación al margen de Franzesi, pero dentro de la tradición bernesca, o sobre un texto escrito cuando don Diego regresa a Espańa a comienzos de los cincuenta, bajo la égida de la revolución conservadora de Felipe II, con lo que el poema se cargaría aún más de sentido contestatario. No creo que se pueda acudir al expediente de un constreñimiento censor o cultural pues el texto solo se difunde en los manuscritos. La alusión de Hidalgo demuestra holgadamente que al menos en 1610 se puede leer pero no publicar, aunque el anotador del ms. 2805 de la Biblioteca de Palacio de Madrid sigue manteniendo una distancia de mucha seguridad en su par de comentarios con respecto a un poema que considera «sucísimo». Un hilo del que tirar es el corresponsal al que se dirige el capitolo con forma epistolar que, según varias fuentes, es el duque de Sessa. Se trata de Gonzalo Fernández de Córdoba (1520 o 1521 - 1578), III duque de Sessa, al que Cetina dedica numerosos poemas. Educado en Granada, este Grande España bien pudo conocer allí a Diego. Gonzalo Fernández de Córdoba era poeta y fue «uno de los más grandes mecenas del Renacimiento hispanoitaliano» (Hernando Sánchez 2009-2012: 775; Ponce Cárdenas 2012: \$22). También Jerónimo de Urrea escribe al duque un poema, fechado en 1547 (Gianesin 2010), y conviene recordar que los poemas de Cetina son necesariamente anteriores a 1554-1557. ¿Estuvo Mendoza en contacto con el duque mientras era embajador en Venecia y en Roma? Si la zanahoria se escribió en ese período ${ }^{57}$ entonces es aún más importante la distancia con Franzesi, si conoció sus textos, o es simplemente prueba de que no pudo leerlos. El duque de Sessa y el marqués de Mondéjar mantuvieron una compleja relación con motivo

57. «[...] es probable que pertenezca al período italiano y sea anterior a 1554 (cuando Mendoza es aceptado como miembro de la Orden de Alcántara)» (Aguirre de Cárcer-Díez 1994: 452). 
de sus respectivas participaciones en la guerra contra los moriscos de Granada y no creo que en esa época don Diego compusiera los tercetos dedicados a la zanahoria. Pero queda claro que don Diego no vertió al castellano los dos poemas de Franzesi, ni los adaptó, ni los resumió: "A la zanahoria» es un poema de aire bernesco pero nuevo. ${ }^{58}$

\section{Entre el negro y el blanco: una cana doble}

No sorprenderá que los textos eróticos, y más si son extensos, se documenten menos en las fuentes que los poemas serios. Pero en la transmisión de la poesía de Mendoza las variaciones son abundantes y las sorpresas también. Así, de los tres poemas cuya fama recoge y reconsagra Hidalgo, la zanahoria se copia hasta trece veces en las fuentes primarias (y una de ellas vuelve al mismo poema en otra ocasión), la pulga nueve y sin embargo la cana solo se documenta en siete cartapacios primarios (no anoto otro tipo de fuentes, recogidas en Hurtado de Mendoza 1989). Pero el fenómeno no es exclusivo de las burlas, pues hay todo un grupo de textos de Mendoza con muchos menos testimonios que otros hasta el punto de configurar un apartado en Hurtado de Mendoza 2007 (363-412). Aquí está el soneto «Libro, pues que vas ante quien puede» y la égloga "Marfira, que te partes y me dejas»; ambos aparecen en el autógrafo, pero la tradición los ha ignorado en gran medida. También hay numerosos textos serios en verso de arte menor (como el bien conocido "Himno al ilustrísimo cardenal de Sigüenza», 380-382) y, por supuesto, varios burlescos o netamente eróticos. ${ }^{59} \mathrm{La}$ transmisión de la poesía de Mendoza no es fácil y, afortunadamente, se resiste a los clichés.

"A una señora que le envió una cana» cuenta con testimonios suficientes para no estar incluida en ese apartado, pero suscita la cuestión del porqué de su compleja transmisión. ¿¿Es un poema más erótico que otros? ¿Es más directo? ¿Gustó menos? ¿Pertenece a la tradición palaciega de las bromas? ¿Es tardío? En la línea de cierta crítica no tan periclitada como sería de desear si alguien se preguntara sobre la edad en la que don Diego experimentó el nacimiento de la primera cana, solo obtendría como evasiva respuesta el juego (que evita la biografía y privilegia lo literario) que se traza en el poema de manera doble: el poeta recibe el envío de

58. Como Mendoza también cultivó la epístola, más o menos horaciana, y no la sátira, es interesante constatar que «il primo nucleo di ternari burleschi del Berni, ascrivibile al 1518-1522, è esattamente contemporaneo alle Satire dell'Ariosto, scritte negli anni 1517-1524” (Longhi 1983: 229). Espero ocuparme en otro trabajo de la discutida influencia de Ariosto en el corpus epistolar de Boscán, Garcilaso y Mendoza (este último disponía de un ejemplar de Le satire de Ariosto [Venecia: 1537; Hobson 1999]).

59. «Empreñose Ginebra la mañana» (372), «¿Sabéis qué me parece, don Gonzalo?» (373-375), y también los textos ya citados como la fábula del cangrejo, los «Consejos», "A una dama entonada» y «A las damas de palacio». La consideración de «A una piedra adonde se asentó su dama» (405), que con tanto acierto incluye Alonso (2001: 61-62) entre los burlescos por su final, podría esconder también un sentido erótico que merecería tratarse detenidamente en otro lugar. 
la cana con la que alguien quiere llamarle viejo y él contesta imaginando de dónde se tomó:

\begin{abstract}
En la cabeza, a mi ver, tener una moza cana es cosa de no creer, que de muy caliente ser venga la fruta temprana (vv. 31-35)
\end{abstract}

Hidalgo conoce el poema y lo sitúa en la tríada que parecería más famosa o que puede citarse sin mucho menoscabo de la gravedad con la que el editor quiere construir la imagen del noble embajador y literato, aunque esa misma gravedad bien entendida impida la edición del poema. Comparte con los otros dos textos aludidos por Hidalgo la presencia de un destinatario, ahora femenino, y tan innominado como en «A la pulga». El «señora» se opone al «compadre» de "A la pulga» y se relaciona también con el «señor compadre» de la zanahoria. ${ }^{60} \mathrm{La}$ cana, a mucha distancia y con una perspectiva absolutamente irónica, se encuadraría en el modo del «regalo» de las composiciones cancioneriles, "poemas en los que se envía (o se agradece) un objeto concreto", en especial dentro de los poemas del s. XVI (entre los que destacan los de Castillejo), con la «marcada tendencia [...] a buscar objetos cada vez más extravagantes» (Alonso 2001: 11 y 47). No es posible en este caso, como en muchos otros, saber si hubo ese «regalo» que motiva el poema o si se trata de una mera excusa para componerlo. ${ }^{61}$ También el poema engarza, a mucha mayor distancia, con otros elogios paradójicos y capilares, ${ }^{62}$ aunque al menos en el caso de Mendoza la orientación es claramente sexual.

Como en "A la pulga", el poema de la cana tiene dos versiones: la más corta, recogida en la mayoría de los manuscritos, ${ }^{63}$ consta de cuarenta y cuatro versos, con dos cuartetas y una estrofa de seis versos en medio de seis quintillas, indicios claros de problemas en la transmisión. De hecho, una de las fuentes, el ms. 70 de la Biblioteca Universitaria de Pennsylvania, trata de regularizar esos fallos con una técnica ingenua: añade a la segunda cuarteta el primer verso de la estrofa de seis, a pesar

60. Según el CORDE la expresión «señor compadre» la utiliza Cervantes hasta en trece ocasiones... aunque no es el único. Hurtado de Mendoza no aparece... quizá porque el CORDE sigue creciendo (consulta del 27 de enero de 2015).

61. Sobre el ingenio del poema, la huida de la denotación y la insistencia del contenido en el erotismo remito a mi sucinto comentario (Hurtado de Mendoza 2007: xlvii-xlviii).

62. Dión Crisóstomo elogió «las melenas, frente al que Sinesio de Cirene rebatió con su Encomium calvorum, uno de los modelos más acabados del género» (Núńez Rivera 1997: 102).

63. Hurtado de Mendoza 2007: 346 (está también en el ms. P, aunque no se indica). LabradorDiFranco (2011a) añaden el ms. VS 62 que no he conseguido consultar (aunque no parece una de las fuentes monográficas de Mendoza) y olvidan el ms. 4268 BNM y el ms. 62 del Seminario de Vitoria. 
de que el sentido chirría junto con la sintaxis. Solo dos manuscritos incluyen una versión larga, de setenta versos ${ }^{64}$ y corrigen las tres irregularidades, con dos versos nuevos y suprimiendo otro en la estrofa de seis. El evidente problema de transmisión se distancia de las diferencias que a su vez acusa «A la pulga», donde la división de las aguas textuales dejaba a un lado una única fuente frente a todas las demás y donde los detalles ya comentados contribuían decisivamente a señalar la versión del ms. 506 BCLM como una amplificación. Ahora resulta mucho más difícil decidir si hay una versión original y otra amplificada, aunque es eso lo que parece.

La poesía erótica parece proclive a las amplificaciones. Así «En loor del cuerno» añade una interpolación de 20 versos, sobre los 181 originales, en una fuente, y seis más en otra ${ }^{65}$ En "A las damas de palacio» el manuscrito llamado Fuentelsol (que no es una fuente primaria de la poesía de Mendoza), le añade 44 versos, mientras otro testimonio bate una suerte de récord al sumar nada menos que ciento ocho más. ${ }^{66}$ También la necia añade versos en el manuscrito sevillano de Toledo, ${ }^{67}$ lo que no es una sorpresa para los lectores de la pulga, desde luego. Y, por contra, «El bombodombón» pierde una estrofa en diversos testimonios. ${ }^{68}$

64. Otros códices, no de los más importantes, interpretan el título: «A una dama que dio una cana a un caballero viejo diciéndole que la había hallado en su cuerpo» o "A una dama que le envió una cana motejándole de viejo», frente a la objetividad de «Sobre una cana».

65. Hurtado de Mendoza (2007: 170-171). Se trata de tres interpolaciones que solo copian dos fuentes que no coinciden: la primera, de 7 estrofas tras el v. 69; la segunda, de dos tras el v. 78; la tercera, dos estrofas tras el v. 84. La primera y la segunda están el ms. 5566 BNM y la tercera en el ms. 354 de la Biblioteca Nacional de Florencia. En la segunda interpolación cabría pensar en que la mención del cuerno de David haya hecho intervenir una suerte de censura, aunque no hay que olvidar que no tiene jurisdicción de hecho en los textos manuscritos. Además, esta segunda interpolación no está compuesta con el cuidado de la primera y las rimas no encajan con la versión canónica. 66. Hurtado de Mendoza (2007: 406). El mismo manuscrito Fuentelsol, que atribuye el texto a Cobos, copia a continuación otra respuesta «del fraile», es decir, de fray Melchor de la Serna (Labrador-DiFranco-Bernard 1997: 129-135) aún más extensa, «en nombre de las damas». El «fraile» parece considerar que la nueva versión es un robo (vv. 21-24 y 27-28) e incluso menciona a don Diego: «Decís cartas de Tanquía / por decirlo el de Mendoza, / y él allá, muerto, se goza / de ver vuestra bobería» (vv. 165-168). Efectivamente la versión atribuida a Cobos no transcribe de modo correcto «ataujía» (Hurtado de Mendoza 2007: 409, v. 89: véase la nota). «El fraile» indica que esta versión ampliada se envía tras la muerte de Mendoza, lo que puede ser muy significativo sobre la confección de textos amplificados (recuérdese el caso de la pulga en el manuscrito sevillano-toledano).

67. La versión atribuida a Cetina en el sevillano-toledano añade quince versos tras el 129 (y modifica, claro está, el v. 128 para enlazar con la rima: «todo va sin sabor, todo lo halla», frente a "todo le huele mal y le parece») y añade tres versos más tras el v. 213. Por eso alcanza una extensión de 256 versos, frente a los 238 del ms. 1578 de la BPM o los 238 de Hurtado de Mendoza (2007: 635-642). E interesante para probar que los añadidos del sevillano de Toledo son eso, ańadidos o amplificaciones, es la versión de otro códice que también atribuye el texto a Cetina y cuenta 238 versos (Labrador Herraiz-DiFranco 2011b: 202-209).

68. Los versos se conservan en la mayoría de las fuentes. Por otro lado se adaptan métrica y temáticamente a la composición: «Salga la sangre que pudo / tu hermosura alterar / y el mezquino tartamudo / que te comenzó a hablar / acabó con sospirar / la palabra y la ocasión, / el bombodombón» (vv. 47-53). 
Es raro que dos fuentes compartan una amplificación, por eso quizá hay que preguntarse si hubo una segunda versión del autor, que corrigiera y ampliara la primera. La estructura no tan fija de los versos de la quintilla se proyecta en oscilaciones y cambios de orden de algunos versos dentro de la estrofa, aunque el sentido no parece sufrir. Pero lo significativo, como decía, es que dos fuentes prefieran una versión más larga que ańade un grupo de cinco quintillas (vv. 36-60). El enlace con los versos anteriores presenta algún problema pues se repiten parcialmente las rimas de la anterior (vv. 36, 38 y 40), lo que vuelve a suceder una vez más en esta sección (la rima de los vv. 42, 43 y 45 es la misma que la de los vv. 47 y 50). Podría ser un indicio de limitación en la técnica poética que no se corresponde con el cuidado de la versión más corta. Además en la primera quintilla «añadida» hay que recurrir a la repetición de «distes» en posición de rima (vv. 37 y 39). Por otro lado el cierre de la serie añadida tiene todos los visos de ser una conclusión:
¡Quién pudiese adivinar
dónde esta cana ha salido, por irse a desenfadar
a tan vicioso lugar
que tan presto ha florecido!
(vv. 56-60).

Aunque la estructura temática independiente de las quintillas hace difícil calibrar las posibles repeticiones que sí se producen, hay que constatar que el engarce de la serie ha cuidado el ajuste con la conclusión real del poema, que juega, en dos quintillas, con la idea de «lugar»e introduce la maligna referencia a una «vela» y al «sol» ("porque el sol quiso bajar», v. 68) al tiempo que insiste en la oscuridad. No es extraño, por otro lado, que el texto termine así pues el «lugar» es el leitmotiv desde el comienzo, pues «cierto fuera mejor obra / decirnos de dónde viene [... ] / ¿quién nos dirá su morada?» (vv. 4-5 y 10).

El manuscrito 1580 de la Biblioteca de Palacio de Madrid no solo copia la cana y la atribuye a Mendoza sino que ¡le añade cinco versos!

\section{$[\ldots]$ que nos andamos gran locura me parece pues de aquí adivinamos que es lo que más deseamos lo que más presto envejece.}

El códice ya en el título amplifica e imagina cuando escribe: «A una dama que dio una cana a un caballero viejo diciéndole la había hallado en su cuerpo». No regulariza, sin embargo, los problemas con las dos cuartetas y la estrofa de seis versos, aunque modifica el orden de todo el texto, pues parte del modelo de 44 versos (el de la versión más documentada) y tras el último ("do nunca suele llegar») es cuando añade las seis quintillas, cinco ya conocidas aunque dispuestas de otro 
modo (vv. 36-45, 56-60, 51-55, 46-50) y la conclusión. El anónimo compilador y poeta ha rehecho el texto en el que sin duda encontraba algún sinsabor, incorpora variantes y lo cierra con una estrofa nueva. Toda una sabia demostración de lo que puede hacer un copista que es mucho más que eso o que siente, como otros, la llamada a probar su ingenio y su técnica literaria en un poema erótico y burlesco.

Una transmisión tan compleja en la cana apunta a una difusión más difícil, precisamente en un texto en octosílabo, frente a la comodidad de la zanahoria y la relativa comodidad de la pulga. Los tres poemas están vinculados a Mendoza, el autor, por el prólogo del primer editor, por la coherencia sistemática de la transmisión manuscrita (a pesar de sus problemas) y por la tendencia a amplificar textos ajenos, aunque no se haya percibido hasta ahora en «la azanahoria, cana, pulga y otras cosas burlescas». 


\section{Bibliografía}

Aguirre de CÁrCer, Luisa Fernanda y J. Ignacio Díez, «Poesía erótico-burlesca y ciencia árabe en los tercetos $A$ la zanahoria», Bulletin of Hispanic Studies, 71.4 (1994), 441-471.

Alonso, Álvaro (ed.), La Carajicomedia, Archidona (Málaga), Aljibe, 1995.

Alonso, Álvaro, Poesía amorosa y realidad cotidiana: del Cancionero General a la lírica italiana, Londres, Department of Hispanic Studies (Queen Mary, University of London), 2001.

—, "Un poema erótico de Cristóbal de Castillejo: "Estando en los baños"», Venus Venerada: tradiciones eróticas de la literatura española, ed. J. Ignacio Díez y Adrienne L. Martín, Madrid, Universidad Complutense, 2006, 39-56.

-, "Castillejo traductor de Ovidio: acerca de un artificio de la poesía erótica», eHumanista, 15 (2010), 38-47.

Arellano, Ignacio, «Las máscaras de Demócrito: en torno a la risa en el Siglo de Oro", Demócrito áureo: los códigos de la risa en el Siglo de Oro, ed. Ignacio Arellano y Victoriano Roncero, Sevilla, Renacimiento, 2006, 329359.

Beccaria Lago, María Dolores, Vida y obra de Cristóbal de Castillejo, Madrid, RAE, 1997.

Blecua, Alberto, «La epístola Al lector a la edición de las Obras de Hurtado de Mendoza (Madrid, 1610): ¿un viejo-nuevo texto cervantino?», Ínsula, 700701 (2005), 2-6.

BоттA, Patrizia, «Algunas calas en la risa áurea y en los problemas de su traducción", Demócrito áureo: los códigos de la risa en el Siglo de Oro, ed. Ignacio Arellano y Victoriano Roncero, Sevilla, Renacimiento, 2006, 75-112.

Cacho Casal, Rodrigo, «La poesía burlesca del Siglo de Oro y sus modelos italianos», Nueva Revista de Filología Hispánica, 51 (2003), 465-491.

—, "Zanahorias y otras picardías: Hurtado de Mendoza ante la tradición bernesca», Caliope, 12 (2006), 13-32.

Carajicomedia, ed. Álvaro Alonso, Archidona (Málaga), Aljibe, 1995.

Castilla, Roberto, El arcediano Antonio Mira de Amescua: biografía documental, Úbeda, UNED, 1998.

Castillejo, Cristóbal, Farsa de la Constanza, ed. Blanca Periñán y Rogelio Reyes, Madrid, Cátedra, 2014.

Cetina, Gutierre de, Rimas, ed. Jesús Ponce Cárdenas, Madrid, Cátedra, 2014.

Corde (Corpus Diacrónico del Español), 27-1-2015, <http://corpus.rae.es/ cordenet.html>

Darst, David H., Diego Hurtado de Mendoza, Boston, Twayne, 1987.

DelPECH, Fançois, «La baigneuse et le crabe indiscret. Nouvelles contributions au folklore érotique», Tigre 7. Travaux des hispanistes de l'Université Stendhal, 1993, 44-68. 
DiFranco, Rafael A., José J. Labrador y Lori A. Bernard, «Una fuente manuscrita inédita para el estudio de la poesía de Diego Hurtado de Mendoza (MP 2805)", La corónica, 24.2 (1996), 103-113.

Díez, J. Ignacio, La poesía erótica de los Siglos de Oro, Madrid, Laberinto, 2003.

—, «Lecturas de una lectura: el manuscrito hablador», "Non omnis moriar». Estudios en memoria de Jesús Sepúlveda, ed. Álvaro Alonso y J. Ignacio Díez, Málaga, Universidad, 2007, 93-113.

—, «Entre el corpus y el canon: selectio y dispositio de los sonetos de Diego Hurtado de Mendoza", Poesías inéditas de Pedro de Padilla y versos de otros ingenios del s. XVI. Ms. B90-V1-08 de la Biblioteca Bartolomé March, ed. José J. Labrador Herraiz y Rafael DiFranco, México, Frente de Afirmación Hispanista, 2011, 49-62.

—, "Esto no sé cómo lo dixo Garci Lasso: opciones del erotismo», AnMal Electrónica, 32 (2012), 321-352. <http://www.AnMal.uma.es/numero32/Garcilaso.pdf>

-, "Obscenidad de ideas y palabras” en el Cancionero de obras de burlas provocantes a risa», Las 'Obras de burlas' del Cancionero general de Hernando del Castillo, ed. Antonio Cortijo Ocaña y Marcial Rubio Árquez, Santa Barbara (California), University of California at Santa Barbara, 2015, 47-83.

Fernández de Moratín, Nicolas, Arte de putear, ed. Isabel Colón y Gaspar Garrote, Archidona (Málaga), Aljibe, 1995.

Gallardo, Bartolomé José, Ensayo de una biblioteca española de libros raros y curiosos, Madrid, Rivadeneyra, 1863-1889, 4 vols.

Garrote Bernal, Gaspar, «A pelo y a pluma: algoritmos de conceptos en Castillejo y La picara Justina (con una digresión para uso de cervantistas)», Tres poemas a nueva luz. Sentidos emergentes en Cristóbal de Castillejo, Juan de la Cruz y Gerardo Diego, Zaragoza, Prensas Universitarias, 2012, 13-45.

Gianesin, Ornella, "La "Carta embiada de don Hierónimo de Urrea al duque de Sessa sobre la presa del duque de Saxonia”", El corazón de la Monarquía. Atti della Giornata Internazionale di Studi, Pavia, 16 guigno 2008, ed. Giusseppe Mazzochi, Pavía: Fundazione Comunitaria di la Provincia di Pavia-Embajada de España en Italia, 2010, 155-190.

González Palencia, Ángel y Eugenio Mele, Vida y obras de don Diego Hurtado de Mendoza, Madrid, Instituto Valencia de don Juan, 1941-943, 3 vols.

GonZalo Sánchez-Molero, José Luis, «Hurtado de Mendoza y Larrea, Antonio", Gran Enciclopedia Cervantina, ed. Carlos Alvar, vol. VI, Madrid, Castalia, 2009, 6044-6045.

Gutiérrez Coronel, Diego, Historia genealógica de la casa de Mendoza, ed. Ángel González Palencia, Madrid, Instituto Jerónimo Zurita-Ayuntamiento de Cuenca, 1946, 2 vols.

Hernando Sánchez, Carlos José, «Fernández de Córdoba, Gonzalo», Diccionario biográfico español, Madrid, RAH, 2009-2012, vol. XVIII, 769-775.

Hobson, Anthony, Renaissance Book Collecting. Jean Grolier and Diego Hurtado de Mendoza, their books and bindings, Cambridge, Cambridge University Press, 1999. 
Hurtado de Mendoza, Diego, Obras del insigne cavallero don Diego de Mendoza, embaxador del Emperador Carlos Qvinto en Roma. Recopiladas por frei Ivan Díaz Hidalgo, del hábito de San Iuan, capellán y músico de cámara de su Magestad, dirigidas a don Íníigo López de Mendoza, Marqués de Mondéjar, conde de Tendilla, señor de la prouincia de Almoguera, año 1610, con priuilegios de Castilla y Portugal, en Madrid, por Iuan de la la Cuesta, véndese en casa de Francisco de Robles, librero del Rey, nuestro seńor.

—, Poesias satíricas y burlescas, [ed. de William I. Knapp] Madrid, Imprenta de Miguel Ginesta, 1876.

—, Obras poéticas, [ed. de William I. Knapp], Madrid, Imprenta de Miguel Ginesta, 1877.

—, Epistolas y otras poesías, pról. Pedro Bohigas, Barcelona, Montaner y Simón, 1944.

—, Poesía completa, ed. J. Ignacio Díez, Barcelona, Planeta, 1989.

—, Poesía, ed. Luis F. Díaz Larios y Olga Gete Carpio, Madrid, Cátedra, 1990.

—, Poesía erótica, ed. J. Ignacio Díez, Archidona (Málaga), Aljibe, 1995.

-, Poesía completa, ed. J. Ignacio Díez, Sevilla, Fundación José Manuel Lara, 2007.

Iommi Echeverría, Virginia, «El movimiento de proyectiles en la Mecánica de Diego Hurtado de Mendoza y la nueva dinámica renacentista", Asclepio. Revista de Historia de la Medicina y de la Ciencia, 63.1 (2011), 179-192.

KIng, Willard F., Prosa novelistica y academias literarias en el siglo XVII, Madrid, RAE, 1963.

Korn, David O., A critical Edition of selected Sonnets of Don Diego Hurtado de Mendoza, Michigan, University of Michigan, 1985, Tesis Doctoral.

Labrador Herraiz, José J. y Rafael DiFranco, «Poesía erótica de Diego Hurtado de Mendoza", Los Mendoza y el mundo renacentista. Actas de las I Jornadas Internacionales sobre Documentación Nobiliaria e Investigación en Archivos y Bibliotecas, ed. Antonio Casado Poyales, Francisco Javier Escudero Buendía y Fernando Llamazares Rodríguez, Tomelloso, ANABAD-Universidad de Castilla La Mancha, 2011a, 107-131.

Labrador Herraiz, José J. y Rafael DiFranco (eds.), Poesías inéditas de Pedro de Padilla y de versos de otros ingenios del s. XVI. Ms. B 90-V1-08 de la Biblioteca Bartolomé March, estudios de Álvaro Alonso, J. Ignacio Díez, Christopher Maurer y Juan Montero, México, Frente de Afirmación Hispanista, 2011b.

Labrador Herraiz, José J., Rafael A. DiFranco y Lori A. Bernard (eds.), Manuscrito Fuentelsol (Madrid, Palacio II-973) con poemas de fray Luis de León, fray Melchor de la Serna, Hurtado de Mendoza, Liñán, Góngora, Lope y otros, seguido ahora de un apéndice con las poesías del fraile benito fray Melchor de la Serna, Cleveland, Cleveland State University, 1997.

—, Poesías de fray Melchor de la Serna y otros poetas del siglo XVI: códice 22028 de la Biblioteca Nacional de Madrid, pról. José Lara Garrido, Málaga, Universidad, 2001. 
Labrador Herraiz, José J., Rafael DiFranco y Juan Montero (eds.), Cancionero sevillano de Toledo. Manuscrito 506 (fondo Borbón-Lorenzana) Biblioteca de Castilla-La Mancha, pról. Begoña López Bueno, Sevilla, Universidad, 2006.

LARA GARRIDO, José, «Lírica tradicional e italianismo: el vario proceso integrador de Hurtado de Mendoza", Del Siglo de Oro (métodos y relecciones), Madrid, Universidad Europea-CEES, 1997, 123-129.

Lasperas, Jean-Michel, «El fondo de librería de Francisco de Robles, editor de Cervantes», Cuadernos Bibliográficos, 38 (1979), 107-138.

Longhi, Silvia, Lusus. Il capitolo burlesco nel Cinquecento, Padua, Antenore, 1983.

Martín, Adrienne L., "Hurtado de Mendoza and the introduction of the bulesque sonnet into Spain", Cervantes and the Burlesque Sonnet, Berkeley, etc., University of California Press, 1991, 41-51.

Martín, Adrienne L. y J. Ignacio Díez (eds.), El eros de Serna como razón de ser: La poesía erótica de fray Melchor de la Serna [monográfico], Canente, 5-6 (2003). Reed. como La poesía erótica de fray Melchor de la Serna (un clásico para un nuevo canon). Anejo LXXVII de Analecta Malacitana (2012).

Martínez Morán, Francisco José, «Mescua, Mira de», Gran Enciclopedia Cervantina, dir. Carlos Alvar, vol. VIII, Madrid, Castalia, 2011, pp. 7866-7868.

Morel-Fatio, Alfred, «Poésies burlesques et satiriques inédites de Diego Hurtado de Mendoza", Jahrbuch für romanische und englische Sprache und Literatur, 2 (1875), 63-80 y 186-209.

NúŃEz Rivera, Valentín, «Tradición retórica y erotismo en los paradoxa enkomia de Hurtado de Mendoza», El Sexo en la Literatura, ed. Luis Gómez Canseco, Laura Alonso Gallo y Pablo Zambrano, Huelva, Universidad, 1997, 99-122.

—, «Para la trayectoria del encomio paradójico en la literatura española del Siglo de Oro. El caso de Mosquera de Figueroa», Actas del IV Congreso Internacional de la Asociación Internacional Siglo de Oro (AISO) (Alcalá de Henares, 22-27 de julio de 1996), ed. María Cruz García de Enterría y Alicia Cordón Mesa, Madrid, Universidad de Alcalá, 1998, II, 1133-1143.

Peña, Margarita (ed.), Flores de baria poesía, México, UNAM, 1980.

Ponce Cárdenas, Jesús, «Cauces de la imitación en el Renacimiento: Gutierre de Cetina y Nicolò Franco», e-Spania. Revue interdisciplinaire d'études hispaniques médiévales et modernes, 13 (2012) <http://e-spania.revues.org/21485> Prieto, Antonio, La poesía española del s. XVI, Madrid, Cátedra, 1984, vol. I.

RADA, Inès, «Expresión del erotismo en la poesía de Diego Hurtado de Mendoza», Edad de Oro, 9 (1990), 241-50.

Rico García, José Manuel, "Gutierre de Cetina», Diccionario Filológico de Literatura Española. Siglo XVI, dir. Pablo Jauralde Pou, Madrid, Castalia, 2009, 237-256.

SepúlvedA, Jesús, "Símbolos del erotismo en la poesía burlesca de Quevedo», Sobre Quevedo y su época. Actas de las Jornadas (1997-2004). Homenaje a Jesús Sepuilveda, ed. Felipe Pedraza y Elena E. Marcello, Cuenca, Universidad de Castilla La Mancha, 2007, 47-67. 
Socas Gavilán, Francisco, "Girolamo Cardano y la biblioteca de don Diego Hurtado de Mendoza", Homenaje al profesor Klaus Wagner: geh hin und lerne, ed. Piedad Bolaños Donoso, Aurora Domínguez Guzmán y Mercedes de los Reyes Peña, Sevilla, Universidad, 2007, I, 427-442.

Sprvakovsky, Erika, Son of the Alhambra. Don Diego Hurtado de Mendoza 15041575, Austin (Texas)-Londres, University of Texas, 1970.

Ureña Bracero, Jesús, «Diego Hurtado de Mendoza y las selecciones de la Antologia Planudea», Florentia Iliberritana: Revista de estudios de antigüedad clásica, 10 (1999), 303-330.

Varo Zafra, Juan, Estudios sobre la prosa de Diego Hurtado de Mendoza, Granada, Alhulia, 2011.

Vega, Lope de, Obras poéticas I, ed. José Manuel Blecua, Barcelona, Planeta, 1969.

Zorita, C. Ángel, José J. Labrador Herraiz y Rafael DiFranco (eds.). Poesías del maestro León y de fray Melchor de la Serna y otros (s. XVI). Códice número 961 de la Biblioteca Real de Madrid, prólogo Dietrich Breisemeister, Cleveland, Cleveland State University, 1991. 